Running Head: How causal is a reciprocal effect?

\title{
How causal is a reciprocal effect? Contrasting traditional and new methods to investigate the reciprocal effects model of self-concept and achievement
} Nicolas Hübner, Wolfgang Wagner, Steffen Zitzmann, \& Benjamin Nagengast University of Tübingen

\author{
Author Note \\ Nicolas Hübner, Institute of Education, University of Tübingen; Wolfgang Wagner, \\ Hector Research Institute of Education Sciences and Psychology, University of Tübingen; \\ Steffen Zitzmann, Hector Research Institute of Education Sciences and Psychology, \\ University of Tübingen; Benjamin Nagengast, Hector Research Institute of Education \\ Sciences and Psychology, University of Tübingen. Access to the data and study material can \\ be requested from the Hector Research Institute of Education Sciences and Psychology. \\ Central analysis code can be found in the Appendix. For additional information contact \\ Nicolas Hübner. Nicolas Hübner is Assistant Professor of Education at the Institute of \\ Education. Correspondence concerning this article should be addressed to Nicolas Hübner, \\ Institute of Education, University of Tübingen, Münzgasse 22-30, 72074 Tübingen, \\ Germany. E-mail: nicolas.huebner@uni-tuebingen.de
}


How causal is a reciprocal effect? Contrasting traditional and new methods to investigate the reciprocal effects model of self-concept and achievement 


\begin{abstract}
The relationship between students' subject-specific academic self-concept and their academic achievement is one of the most widely researched topics in educational psychology. A large body of this research has considered cross-lagged panel models (CLPMs), oftentimes synonymously referred to as reciprocal effects models (REMs), as a gold standard to investigate the causal relations between the two variables and has reported evidence for a reciprocal relationship between self-concept and achievement. However, more recent methodological research questioned the plausibility of assumptions that need to be satisfied in order to interpret results from traditional CLPMs causally. In this substantive-methodological synergy, we aimed at contrasting traditional and more recently developed methods to investigate reciprocal effects of students' academic self-concept and achievement. Specifically, we compared results from CLPMs, from full forward CLPMs (FF-CLPMs), and from random intercept CLPMs (RI-CLPMs) with two weighting approaches developed to study causal effects of continuous treatment variables. To estimate these different models, we used rich longitudinal data of $N=3,757$ students from lower secondary schools in Germany. Results from CLPMs, FF-CLPMs, and weighting methods support the reciprocal effects model, particularly when considering math self-concept and grades. In contrast, results from the RI-CLPMs were less consistent. Implications from our study for the interpretation of effects from the different models and methods as well as for school motivation theory are discussed.
\end{abstract}

Keywords: substantive-methodological synergy, reciprocal effects model, selfconcept, cross-lagged panel model, entropy balancing 
Educational Impact and Implications Statement

Over the past years, different statistical models were developed to investigate whether self-concept influences achievement, whether achievement influences self-concept, or whether both influence each other. In this substantive-methodological synergy, we investigated the relation between self-concept and achievement using traditional and also new methods that explicitly allow to identify causal relationships between continuous variables. Using these new methods, we found evidence in favor of the reciprocal effects model, which assumes that self-concept positively affects achievement and achievement positively affects self-concept over time. 
How causal is a reciprocal effect? Contrasting traditional and new methods to investigate the reciprocal effects model of self-concept and achievement

Researchers in educational psychology have put considerable effort into investigating reciprocal relations between self-concept and student achievement (e.g., Huang, 2011; Marsh \& Craven, 2006; Valentine et al., 2004; Wu et al., 2021). Academic self-concept reflects a person's perceptions about their abilities formed through the environment (Marsh, 1990b; Marsh et al., 2016; Shavelson et al., 1976). Positive self-concepts are seen to have many desirable effects, particularly related to academic outcomes (Brunner et al., 2010; Huang, 2011), but also regarding psychological and physical health and child development (Marsh \& Martin, 2011; Möller et al., 2009).

Since the 1970s, three concurring models have been formulated (e.g., Arens et al., 2017): the skill development model, which assumes that achievement influences self-concept; the self-enhancement model (Calsyn \& Kenny, 1977; Valentine et al., 2004), which assumes a reverse pattern; and the reciprocal effects model (REM; Marsh, 1990a), which assumes that both constructs are reciprocally related. These three models have typically been investigated using statistical models from the family of cross-lagged panel models (CLPMs; e.g., Marsh \& Craven, 2006; Usami et al., 2019) claiming to investigate "causal relations between academic achievement and academic self-concept" (Marsh \& Craven, 2006, p. 151). Thus, specific patterns of results of the cross-lagged parameters were often interpreted causally and as evidence in favor of one of the three models outlined above (e.g., Helmke \& van Aken, 1995; Marsh et al., 2005; Marsh \& Martin, 2011; Pinxten et al., 2010; Sewasew et al., 2018).

However, the assumptions under which statistical relations in CLPMs can be interpreted causally have been seldom made explicit. Methodological research suggested that neither longitudinal data nor the specification of a CLPM per se is sufficient for estimating causal effects (e.g., Hamaker et al., 2015; Rogosa, 1980). More specifically, Usami et al. 
(2019) argued that the assumptions required for CLPMs to allow for a causal interpretation might be rather unrealistic in practice. They suggested that weighting methods might provide promising alternatives to satisfy these assumptions and indeed estimate causal effects. This leaves applied self-concept researchers with two sets of challenging questions: First, what are the assumptions for causal inference made by weighting methods and how likely are they satisfied when investigating reciprocal effects between self-concept and achievement? Second, is there evidence for reciprocal effects of academic self-concept and achievement when using these methods for causal inference and how do results from traditional and new methods compare to one another? In addressing these questions, we will investigate reciprocal relations between student self-concept and achievement using (a) traditional CLPMs, (b) FF-CLPMs (e.g., Lüdtke \& Robitzsch, 2021), (c) RI-CLPMs (Hamaker et al., 2015), and (d) two weighting approaches (covariate balanced generalized propensity score weighting [CBGPS-weighting] and entropy balancing [EB]). The two weighting approaches were explicitly developed to study causal effects of continuous treatment variables in observational studies (Fong et al., 2018; Hainmueller, 2012; Tübbicke, 2021). The results of this substantive-methodological synergy (Marsh \& Hau, 2007) will shed new light on one of the core topics of prior educational psychological research, the reciprocal relations of student self-concept and achievement, and the robustness of these relations under different assumptions for causal inference.

\section{The Interplay Between Student Motivation and Achievement}

Over the past decades, many studies investigated the association between students' self-concept and their achievement (e.g., Arens et al., 2017; Huang, 2011; Wu et al., 2021). Academic self-concept reflects a person's perceptions about their abilities, formed through the environment (Marsh, 1990b; Marsh et al., 2016; Shavelson et al., 1976). Positive selfconcepts have been discussed as potential gateways to enhance student learning via specific 
targeted interventions and educational reforms (Uchida et al., 2018; Valentine et al., 2004) and as a mediator for a host of further desirable social-emotional and behavioral outcomes (O'Mara et al., 2006). The statistical models from this research consistently show reciprocal relations between academic self-concept and achievement, that is, positive partial regression coefficients. However, if and under which assumptions these relations can be interpreted as representing causal effects is an open question that is seldom addressed by substantive researchers.

In a meta-analysis, Huang (2011) investigated longitudinal relations between prior self-concept and achievement (i.e., grades or test scores) with subsequent achievement and self-concept using data from 39 independent samples. The study reported average correlations between $r=.20$ and .27 between prior self-concept and post achievement and correlations between $r=.19$ and .25 between prior achievement and subsequent self-concept, which were interpreted as evidence in favor of reciprocal relations. Another, more recent meta-analysis by $\mathrm{Wu}$ et al. (2021), which considered results from 68 longitudinal studies, found that prior achievement significantly predicted subsequent self-concept $(\beta=0.16, p$ $<.01)$ after accounting for prior self-concept scores. In addition, prior self-concept predicted subsequent achievement $(\beta=0.08, p<.01)$ after accounting for prior achievement scores. Notably, this study also suggests that self-concept might be more strongly related to grades than to achievement in standardized tests. The authors argue that grades are often based on high-stakes assessments, which have strong implications for students and are therefore strongly influenced by motivational student characteristics, whereas achievement assessed in standardized achievement tests in educational studies are typically more low-stakes and therefore less strongly influenced by students' self-concept (e.g., Arens et al., 2017; Hübner, Spengler, et al., 2021; Marsh et al., 2005; Wylie, 1979). Further studies have extended these findings by focusing on dimensional comparisons (e.g., internal and external frames of 
reference). A meta-analysis by Möller et al. (2020) found substantial positive path coefficients between achievement and self-concept in similar subjects but substantial negative path coefficients in dissimilar subjects. Taken together, these studies provide important evidence in favor of reciprocal relations between self-concept and student achievement. But whether and under which assumptions these partial regression coefficients can be interpreted as causal has received little attention in substantive research on this topic.

\section{Challenges and Assumptions of Interpreting Cross-lagged Coefficients as Causal: A Potential Outcome Perspective}

Usami et al. (2019) have provided a comprehensive overview of requirements for causal inference in cross-lagged panel models based on the Rubin causal model (Rubin, 1974). The Rubin causal model defines causal effects in terms of potential outcomes: Y(1) would be the potential outcome of a person in the treatment condition $(T=1)$ and $Y(0)$ would be the potential outcome of a person in the control condition $(\mathrm{T}=0)$. Rubin defined the difference between these two potential outcomes $(\mathrm{Y}(1)-\mathrm{Y}(0))$ as the individual causal effect and the average of all individual causal effects as the average causal effect (e.g., Shadish, 2010; West \& Thoemmes, 2010). Lüdtke and Robitzsch (2021) applied this framework to define the cross-lagged causal effect. Translated to the REM, one would define the causal cross-lagged effect of self-concept on grades as the following linear function:

$$
\mathrm{E}\left(G_{i 3}\left(s c_{2}\right)\right)=\beta_{0}+\beta_{1} s c_{2}
$$

where the outcome, the grades received by individual i $\left(G_{i 3}\right)$, given a specific value of selfconcept $\left(\mathrm{SC}_{2}=\mathrm{sc}_{2}\right)$ is predicted by an intercept $\beta_{0}$ and the causal effect $\beta_{1}$. Here, $\beta_{1}$ constitutes the causal effect of increasing self-concept at the second measurement occasion by one unit on grades at the third measurement occasion. Usami et al. (2019) outlined three assumptions that need to be satisfied in order for CLPMs to identify causal effects: (a) consistency, (b) strong ignorability/no unobserved confounding, and (c) positivity (see also 
Lüdtke \& Robitzsch, 2021). Referencing to Rubin's potential outcome framework (e.g., Holland, 1986; Rubin, 1974, 2004), consistency implies that the observed outcome of a person is identical to the potential outcome of this person, given her/his observed exposure history (Rehkopf et al., 2016). The strong ignorability/no unobserved confounding assumption requires that all potentially confounding variables are measured and adequately considered in the respective model (Rosenbaum \& Rubin, 1983). Finally, the positivity assumption requires that all treatment $\times$ covariate combinations exist in the population. Practically, this suggests that sufficient overlap is required on the covariate distribution for different values of a treatment variable (Kang et al., 2016).

\section{Challenges and Assumptions of Interpreting Results of CLPMs as Causal: A Structural Causal Model Perspective}

A conceptual look at the REM seems helpful to derive potentially reasonable structural causal models on the relation between self-concept and achievement from the literature. Structural causal models are models of reality, which display considerations and assumptions about causal relations between variables (Cunningham, 2021; Lüdtke \& Robitzsch, 2021; Pearl et al., 2016). They consist of exogenous and endogenous variables, operators (arrows), which indicate the direction of the respective causal effects (see Figure 1), and any functional form to link the two types of variables (not displayed). One can easily apply these models to a scenario in which we would like to know the causal effect of selfconcept (SC) on grades (G): For such situations, Pearl et al. (2016) have introduced the dooperator to indicate the counterfactual of interest that arises when, for instance, self-concept (SC) is set to a specific value (e.g., $\operatorname{do}(\mathrm{SC}=\mathrm{sc})$ ), which results in the interventional distribution of $P(\mathrm{G}=\mathrm{g} \mid$ do $(\mathrm{SC}=\mathrm{sc}))$. Importantly, as outlined in more detail by Voelkle et al. (2018) for defining and identifying the causal effect, it is not necessary to be able to 
physically manipulate a variable in the real world (e.g., by setting SC to sc). Based on this, structural causal models are assumed to display causal relations (Pearl, 2009).

In contrast, statistical models such as structural equation models (e.g., CLPMs), which are typically used in educational psychological literature on reciprocal relations between selfconcept and achievement (e.g., Arens et al., 2017; Ehm et al., 2019), are based on linear regressions and related to specific data. Such statistical models have a specific causal interpretation only if they are linked to a counterfactual framework (e.g., structural causal models) via specific identification rules. These statistical models can therefore be understood as vehicles to estimate structural causal models.

Based on prior research on reciprocal relations between self-concept and achievement, particularly three types of structural models have been discussed (e.g., Huang, 2011; Marsh et al., 2005; Marsh \& Craven, 2006; Preckel et al., 2017; Seaton et al., 2015; Sewasew et al., 2018; Wu et al., 2021), depicted in Figure 1: a model with prior scores predicting post scores (a); a model with additional lag-2 effects (e.g., with additional paths from the first to the third measurement occasion), also referred to as full-forward model (b); and a model with lag-2 effects and additional confounders (c).

In the simplest structural model (a) derived from the respective REM literature (e.g., Arens et al., 2017; Preckel et al., 2017), self-concept, grades, and test achievement (SC, G, and $\mathrm{T}$ in Figure 1) are assumed to be reciprocally related. This means that the structural causal model assumes paths from all preceding variables to all variables at the next assessment timepoint. This model is indeed very (and probably overly) restrictive: It presumes that there are no other time-constant and time-varying variables that simultaneously influence academic self-concept and achievement (e.g., no hidden confounders, backdoor paths) and that there are no additional lagged effects (e.g., carry-over effects). In practice, this model seems unrealistic: It is well known that achievement and self-concept are typically 
related to many variables beyond self-concept and achievement, such as socioeconomic status, gender, or school type (Chmielewski et al., 2013; Hübner et al., 2017; Sirin, 2005; Voyer \& Voyer, 2014), and prior studies have found evidence for carry-over effects, particularly on autoregressive but also on cross-lagged coefficients (e.g., Arens et al., 2017; Ehm et al., 2019; Preckel et al., 2017).

Structural model (b) is similar to model (a) but additionally includes lag-2 effects (e.g., T1 to T3 etc.). Specifically, this model would imply that all preceding variables have effects on subsequent variables, but that self-concept, grades, and test achievement at the very first occasion also have long-term effects (e.g., carry-over effects) on all variables at the third measurement occasion. This model is more plausible as empirical results show that fullforward autoregressive and cross-lagged coefficients are quite commonly predictive in REMs (e.g., Arens et al., 2017). However, it still leaves out other confounding variables that are time-invariant properties of the students and time-varying states at the different measurement occasions.

Finally, structural model (c) is similar to model (b) but also includes a vector of confounding variables that might be time-invariant or time-varying. For instance, as prior empirical research suggests, girls and boys differ in their math self-concept, and prior studies also reported gender differences on math achievement to some extent, which would be required to control for (e.g., Hübner et al., 2017; Watt et al., 2012; Watt et al., 2017). Furthermore, if confounders change their association with grades, achievement tests, and selfconcept over time (time-varying confounders), these would be required to be controlled for in the model. Considering prior research on self-concept and achievement, this structural causal model seems to be most realistic compared to (a) and (b), as it explicitly considers confounders, which influence the different variables in the REM. 


\section{Recent Methodological Advancements to Investigate Reciprocal Relations}

In recent years, several statistical models were discussed that aimed to overcome shortcomings of the traditional CLPM with regard to confounders: the RI-CLPM, the FFCLPM, and weighting methods. All of these models come with specific assumptions and requirements to reveal cross-lagged causal effects (see Table 1).

RI-CLPM. In 2015, Hamaker et al. introduced the RI-CLPM, a model that adds random intercepts to the CLPM. The conceptual idea for this model resulted from a multilevel perspective on longitudinal data, whereby repeated observations are nested within individuals. Technically, the CLPM is nested under the RI-CLPM, and both models are identical if the variances and covariances of the random intercept factors are set to zero (Hamaker et al., 2015). The specific advantage of the RI-CLPM over the CLPM, particularly in regard to causal inference, was argued to result from the fact that it separates processes taking place within individuals from time-stable observed and unobserved differences between individuals. The idea of eliminating this time-stable between-person variation is less prominent in educational psychology but more common in econometric panel analysis, for instance, when using unit-centering or adding unit-dummy-variables to regression models (Hamaker \& Muthén, 2020). Related to this, Usami et al. (2019) outlined that the RI-CLPM relaxes some of the strong assumptions inherent in CLPMs: It requires strong ignorability and positivity assumptions to hold only after controlling for time-invariant differences between individuals.

FF-CLPM. Most recently, Lüdtke and Robitzsch (2021) raised fundamental concerns regarding the superiority of the RI-CLPM over the CLPM for investigating causal effects. Using simulated data, they showed that RI-CLPMs are not necessarily able to control for unobserved confounding (as suggested by Hamaker et al., 2015). Most interestingly, in their simulation study, Lüdtke and Robitzsch generated data for two variables $\mathrm{X}$ and $\mathrm{Y}$ based on a 
CLPM with three measurement occasions, and showed that "the estimates of the RI-CLPM were only unbiased in data conditions in which the correlations of the confounder with $\mathrm{X}$ and $\mathrm{Y}$ were constant across time (condition $\mathrm{C} 4$ ), or if the correlations of $\mathrm{X}$ and $\mathrm{Y}$ with the confounder decreased by the same factor across time (condition C1)" (p. 16). However, in these situations, all models (i.e., also the CLPM and the FF-CLPM) produced almost unbiased estimates of cross-lagged coefficients. Based on these findings, Lüdtke and Robitzsch highlight the value of considering FF-CLPM when cross-lagged effects are of interest.

Weighting methods. All longitudinal models outlined above come with assumptions for identifying causal effects that are less plausible in applications of the REM: First, CLPMs allow causal inference only in the absence of lag-2 paths and confounding variables, which seems implausible when investigating reciprocal relations between self-concept and achievement. Second, RI-CLPMs can control for observed and unobserved time-invariant confounders, but as shown by Lüdtke and Robitzsch (2021), the application of these models seems limited, and oftentimes, these models do not outperform traditional models such as the FF-CLPM. In addition, when using these models, applied researchers typically do not control for time-varying covariates. Related to this, researchers have suggested weighting methods as alternatives to traditional models (e.g., Robins et al., 2000; Thoemmes \& Ong, 2016; Usami et al., 2019) because they facilitate controlling for a large set of observed time-varying and time-stable covariates and also require to explore and optimize covariate balance, before actually estimating treatment effects.

Therefore, from a causal perspective and from a substantive perspective on the REM, these models seem more likely to satisfy the strong assumptions required for causal inference, particularly the strong ignorability assumption and particularly compared to the CLPM, if relevant confounders were assessed (see Table 1). In order to understand these methods, it is 
helpful to start by considering the example of inverse probability weighting, which typically follows a three-step procedure as outlined by Thoemmes and Ong (2016) or Pishgar et al. (2021): In a first step, researchers specify a selection model and predict a treatment variable of interest from a comprehensive set of covariates assessed prior to the treatment. Based on this selection model, weights are estimated, using information about the individual's probability of having a specific value on the treatment variable. Next, covariate balance is inspected and optimized if needed. Finally, the weighted (i.e., covariate balanced) samples are used to estimate treatment effects (see also Figure 2). Recently, there have been major methodological advancements of these weighting methods in the field of statistics in terms of extensions of algorithms for dichotomous treatment variables to continuous treatment variables such as entropy balancing (EB; Hainmueller, 2012; Tübbicke, 2021) or covariate balanced generalized propensity score weighting (CBGPS; Fong et al., 2018; Imai \& Ratkovic, 2014). These methods allow to estimate the causal effect of continuous variables such as self-concept (T2) on achievement (T3) after all prior covariate differences are controlled for.

When comparing the assumptions of the different statistical models with the structural causal models (see Figure 1), it becomes evident that if the structural causal model is similar to (a) or (b), the CLPM and the FF-CLPM are adequate choices for causal inference: More practically speaking, if associations between self-concept and achievement are similar to (a; no 2-lag paths and confounder) or (b; no confounder), statistical models such as the CLPMs /FF-CLPMs will reveal adequate causal effects. As outlined above, this seems unrealistic in the context of REM. Regarding (c) different suggestions were outlined in the literature. Whereas some studies have argued that RI-CLPMs constitute a reasonable improvement to test this model, particularly regarding time-invariant confounders (e.g., Hamaker et al., 2015), others have challenged this proposition (Lüdtke \& Robitzsch, 2021), and yet other studies 
suggested that different methods might be even more promising in such contexts (e.g., weighting techniques; Usami et al., 2019). Most importantly, if model (c) is the structural causal model with time-invariant and time-varying confounders, then common specification of the CLPM, the FF-CLPM, and the RI-CLPM will not reveal the desired causal effects of self-concept on achievement and vice versa, because then the estimated coefficients are biased due to unconsidered confounders.

\section{The Present Study}

The present study constitutes a substantive-methodological synergy (Marsh \& Hau, 2007) to investigate relations between self-concept and achievement using different traditional and more recently developed methods. Specifically, we go beyond prior research and apply new weighting methods to estimate causal effects of self-concept on achievement and vice versa. These methods were developed to identify causal effects of continuous treatment variables and have many desirable features regarding causal inference, particularly regarding the strong ignorability assumption (see Table 1).

Our study will therefore produce new insights on the existence and directions of reciprocal effects of self-concept and achievement. We will investigate reciprocal relations between student motivation and achievement using (a) traditional CLPMs; (b) suggested extensions of these models, namely FF-CLPMs (Lüdtke \& Robitzsch, 2021); and (c) the RICLPM (Hamaker et al., 2015). In addition to these three types of longitudinal structural equation models, we will apply two weighting approaches, entropy balancing (EB) and covariate balanced generalized propensity score weighting (CBGPS), to study causal effects of the two variables on one another. Based on prior research, we assume that traditional models such as the CLPM and the FF-CLPM (Huang, 2011; Wu et al., 2021) will yield reciprocal effects of academic self-concept and achievement, particularly when high-stakes grades are considered rather than low-stakes standardized achievement tests without any 
feedback to students about their test results. In addition, based on prior findings, we assume that cross-lagged coefficients in the RI-CLPM should be smaller and respective standard errors should be larger than in the CLPM and the FF-CLPM (e.g., Bailey et al., 2020; Burns et al., 2020; Ehm et al., 2019; Lüdtke \& Robitzsch, 2021; Mulder \& Hamaker, 2021). Finally, we are not aware of any studies that have used the new weighting approaches to investigate the effect of self-concept on achievement or vice versa. However, as outlined above, we suggest that these methods show favorable characteristics in regard to the assumptions required to identify causal effects, particular the strong ignorability assumption. Theoretically, it seems reasonable to believe that CLPMs might overestimate cross-lagged coefficients to some degree, if relevant confounding variables are ignored, which actually explain variation in the dependent variable (e.g., general cognitive ability, personality, achievement in other subjects, effort, etc.). However, not controlling for these confounders might also lead to a suppression of the true associations between REM variables. Therefore, whether or not we find evidence in favor of the REM using these new methods remains to be shown.

\section{Methods}

\section{Data}

To investigate differences between the results from the different methods, we used data from the Transition and Innovation (TRAIN) study hosted by the Hector Research Institute of Education Sciences and Psychology at the University of Tübingen in Germany (Jonkmann et al., 2013). Starting in 2008, this study repeatedly assessed students once a year during lower secondary school (from Grade 5 to Grade 8). In the TRAIN study, overall, $N=$ 3,880 students participated at each measurement occasion. Here, we considered only the subset of students who participated in the mathematics assessment test, resulting in a sample of $n=3,757$ students ( $45.3 \%$ female) from 136 classes in 105 schools. We considered data of 
all individuals who participated at least once in the 4 years, resulting in a sample of $n=2,869$ students in Grade 5 (44\% female), $n=2,925$ students in Grade 6 ( $45 \%$ female), $n=2,969$ students in Grade 7 (46\% female), and $n=2,985$ students in Grade 8 (46\% female). The majority of students participated in all four waves $(n=2,206)$. The sample consists of students from lower secondary school in two German states (Baden-Württemberg [65.9\%] and Saxony). At the first measurement occasion, students were on average 11.2 years old. Access to the data and study material can be requested from the host of the study (see above). Central analysis code can be found in the Appendix. We did not preregister this study. The TRAIN study was approved by the Ministries of Education in the respective states.

\section{Instruments}

As further outlined below, we considered students' math self-concept, standardized test achievement, and grades, and an additional rich set of covariates, which were assessed at all four measurement occasions.

Subject-specific Self-concept in Mathematics. Students' self-concept in mathematics was assessed using a German version of the Self Description Questionnaire (SDQ) III (Marsh, 1992; Schwanzer et al., 2005). The instrument consisted of four items (e.g., "I am good in mathematics"), and students were required to rate their agreement from 1 (does not apply at all) to 4 (completely applies). Items with negative wording were reverse-coded. Reliability of the items as indicated by Cronbach's Alpha was high (ranging from $\alpha=.78$ to .86 across waves).

Achievement in Mathematics. Students' achievement in mathematics was assessed using a standardized mathematics test oriented at the national standards for lower secondary school. Overall, 40 minutes of time were assigned for the math test. The test consisted of 7487 items per measurement occasion, which were administered in a multi matrix design so that students had to work on 41-45 items per assessment. The majority of items were taken from 
prior large-scale studies such as ELEMENT (Lehmann \& Lenkeit, 2008) or BIJU (Baumert et al., 1996) and assessed primarily math literacy using exercises from five different guiding areas: number, measuring, shape and space, functions, and data and chance. We used 20 plausible values, which were generated using a 2PL item response theory (IRT) model (Rose et al., 2013). The average WLE reliability of the test was .74, ranging from .71 to .77. In addition, grades were assessed based on teacher report at each measurement occasion, ranging from 1 (very good) to 6 (worst possible grade). We reverse-coded grades so that higher values reflect better achievement.

Covariates. We also considered a broad set of covariates, which were used when applying the weighting approaches. When deciding which variables to consider, we followed recommendations from prior studies and applied an inclusive strategy (Thoemmes \& Kim, 2011; Vanderweele, 2019; Vanderweele et al., 2020). Based on this, we included five sets of variables: (1) demographic variables (e.g., school type, gender, and age), (2) variables related to the socioeconomic background of the student (e.g., migration background, socioeconomic background, and books at home), and (3) variables related to student achievement (e.g., standardized achievement in English) and general cognitive abilities. In addition, we considered (4) motivational variables such as self-concepts in German and English and students' subject-specific interests and effort in mathematics, German, and English. Finally, we also considered variables related to (5) students' well-being, as well as the Big Five personality traits. Variables related to (3), (4), and (5) were considered as time-varying variables in the analysis of data from Grades 6 to 8 (see Statistical Analysis section). Generally, we considered all available variables in the data set that could act as confounders of the relation between achievement and self-concept, as suggested in the respective methodological literature (Vanderweele, 2019). A comprehensive list of all variables considered can be found in Appendix A1. 


\section{Statistical Analysis}

The main statistical analysis followed three steps: First, we inspected and multiply imputed missing data. Next, we specified the respective longitudinal structural equation models. Finally, we applied the EB and CBGPS-weighting approaches.

Inspection and Multiple Imputation. In the first step, we identified the relevant variables and compiled the data of the TRAIN study in R 4.1.1 (R Development Core Team, 2021). Next we specified a multilevel imputation model in Mplus 8.6 (Muthén \& Muthén, 1998-2017) with the school ID as cluster variable, which resulted in 20 complete data sets. Before multiple imputation, missing data on the outcome variables ranged between $1 \%$ (Grade 8) and 9\% (Grade 5) on math grades and between 17\% (Grade 8) and 28\% (Grade 5) on math self-concept. For standardized math achievement, missing values ranged from $3 \%$ (Grade 5) to 8\% (Grade 6). Here we used the provided plausible values of the data set (e.g., Rose et al., 2013). Data were transferred to Mplus using the MplusAutomation package (Hallquist \& Wiley, 2018).

Specification of Longitudinal Structural Equation Models. Following this, we specified (a) the CLPM, (b) the FF-CLPM, and (c) the RI-CLPM in Mplus. An annotated exemplary Mplus code for the RI-CLPM can be found in Appendix A2. In line with Lüdtke and Robitzsch (2021), we focused on cross-lagged coefficients between variables assessed at the second (T2) and the third (T3) and, in separate models, the third (T3) and the fourth (T4) measurement occasions (see Table 2) in our comparison, because these are the coefficients that can be received from the weighting approaches, which require to distinguish between a) pre-treatment variables (T1/T2), b) treatment variables (T2/T3), and post-treatment outcomes (T3/T4). This means that in order to estimate causal effects, weighting approaches require variables assessed prior to the treatment variable, which cannot be influenced by the respective treatment variable itself (e.g., Hübner, Trautwein, \& Nagengast, 2021; Thoemmes 
\& Kim, 2011; Thoemmes \& Ong, 2016). Therefore, we ran two sets of models, each considering three measurement timepoints (i.e., Grades 5-7 and Grades 6-8). When estimating models using data from Grades 5-7, we were interested in coefficients for the Grades 6-7 time-lag, and when estimating models using data from Grades 6-8, we were interested in the respective Grades 7-8 coefficients. Based on prior recommendations (Orth et al., 2021), we provide results from models with and without equality constraints on lag-1 paths. These models assume that cross-lagged and lag-1 autoregressive coefficients are similar across time and are most prominently used in current REM literature (Usami et al., 2019).

The specification of the respective models closely followed recent recommendations (e.g., Mulder \& Hamaker, 2021). As outlined in prior research (Hamaker et al., 2015), the CLPM is nested under the RI-CLPM. Therefore, in the CLPM and the FF-CLPM, the variances and covariances of the random intercepts were fixed to zero. The FF-CLPM also included additional lag-2 coefficients to predict variables assessed at measurement occasion $t$ from variables assessed at measurement occasions $t$ - 1 and $t$-2 (Lüdtke \& Robitzsch, 2021).

Specification of Weighting Approaches. Following the specification of the longitudinal structural equation models, we specified the weighting approaches in $\mathrm{R}(\mathrm{R}$ Development Core Team, 2021). Specifically, we made use of the MatchThem package (Pishgar et al., 2020), which extends functionalities of the WeightIt package (Greifer, 2021b) in such a way that models can be run with multiply imputed data sets. Figure 2 illustrates the general procedure and steps of the applied weighting approach for estimating the causal effect of self-concept on grades. Appendix A3 shows exemplary R code for a similar scenario.

In our study, first (selection step), three different selection models where specified in which either test achievement, self-concept, or grades in mathematics assessed at T2 was 
predicted by achievement, self-concept, and grades in mathematics plus a large set of covariates assessed prior to T2 (i.e., T1; see Instruments section). These three selection models revealed three sets of weights. Before running these models, all continuous variables were standardized to resemble $M=0$ and $S D=1$ across all imputed data sets using the miceadds package (Robitzsch et al., 2021), so that the results can be interpreted in terms of units of standard deviations. We estimated weights separately for each imputed data set (i.e., the within approach; Leyrat et al., 2019) using (i) the EB method (Tübbicke, 2021) and (ii) the CBGPS-weighting method (Fong et al., 2021). EB for continuous variables relies on a reweighting scheme that minimizes the loss function and imposes normalization constraints (i.e., weights have to be positive and sum up to one). Practically speaking, EB reweights all participants to achieve a correlation of zero between covariates and the treatment variable (Tübbicke, 2021). The reweighting scheme therefore assures double robustness (Zhao \& Percival, 2017). The CBGPS approach constitutes a parametric extension of the CBPS approach for binary treatment variables of Imai and Ratkovic (2014) to continuous variables. CBGPS applies a homoscedastic linear model to estimate the generalized propensity score and to minimize the covariate treatment correlation (Fong et al., 2018).

In a next step (inspection step), we inspected the weights and the correlation between covariates and the respective treatment variables (covariate balance) before and after weighting, using different functions from the cobalt package (Greifer, 2021a; see Figure 3). A common challenge when applying weighting approaches is that sometimes unrealistically large weights are estimated (Thoemmes \& Ong, 2016). Ignoring large weights can yield unbiased, but imprecise estimates (Cole \& Hernán, 2008). In our study, large weights resulted when applying CBGPS weighting. Based on the literature cited above, we decided to estimate 1\%-trimmed weights to assess the robustness of our findings (see Thoemmes \& Ong, 2016). 
Following this (analyzing step), we used the survey package (Lumley, 2018) to specify multiple regression models in which we predicted $\mathrm{T} 3$ variables (i.e., achievement and self-concept) using the variables from T2 (i.e., achievement, self-concept, and covariates; Schafer \& Kang, 2008), the respective sets of balancing weights from the first steps (see above), and cluster-robust standard errors. Finally (pooling step), we pooled the results from these 20 regression models using Rubin's rules (Rubin, 1987). A similar procedure was applied when investigating effects of $\mathrm{T} 3$ on $\mathrm{T} 4$ variables.

\section{Results}

\section{Preliminary Results}

First, we inspected correlations between the different variables, which are displayed in Table 3. As can be seen, correlations between matching constructs ranged from $r=.73$ to .83 for math test achievement, from $r=.37$ to .60 for math self-concept, and from $r=.41$ to .65 for grades (all $p<.001$ ). Correlations between subsequent measurement occasions (lag-1; e.g., G5 and G6 or G6 and G7) were stronger compared to lag-2 correlations (e.g., G5 and G7), which is in line with prior REM research (e.g., Ehm et al., 2019). Taken together, these results suggest that the different constructs seem to be relatively stable over time.

Next, we had a closer look at correlations of non-matching constructs. Although, as outlined above, these were also statistically significantly related $(p<.001)$, they were smaller. For instance, the correlations between standardized test achievement and selfconcept in mathematics ranged from $r=.23$ to .31 and the correlations between grades and self-concept ranged from $r=.20$ to .41 . Grades and self-concept correlated slightly higher compared to standardized test achievement and self-concept (on average $\Delta r=.04$ ), which was argued in prior studies to result from the fact that grades reflect motivational aspects of student behavior more strongly (Wu et al., 2021; Wylie, 1979). Similar to our findings for 
matching constructs, correlations between lag-1 paths tended to be larger compared to correlations between lag-2 paths.

\section{Results from CLPMs, FF-CLPMs, and RI-CLPMs}

Model Fits. In the next step, we inspected the model fits of the specified CLPMs (see Table 4). For each of the three types of longitudinal structural equation models, we specified two types of models, one without and one with equality constraints over time (see Statistical Analysis section). Table 4 displays model fit statistics for CLPMs without equality constraints $\left(\chi^{2}(9)=359.27, p<.001, \mathrm{RMSEA}=.10, \mathrm{CFI}=.97, \mathrm{TLI}=.89, \mathrm{SRMR}=.03 ; \mathrm{Hu}\right.$ $\&$ Bentler, 1999) and for CLPMs with equality constraints $\left(\chi^{2}(18)=485.80, p<.001\right.$, $\mathrm{RMSEA}=.08, \mathrm{CFI}=.96, \mathrm{TLI}=.93, \mathrm{SRMR}=.05)$. These results were similar for CLPMs from Grade 5 to Grade 7 and for CLPMs from Grade 6 to Grade 8.

Regarding the FF-CLPM, we found a slightly different picture. Here, fits for the model with the respective lag-1 equality constraints revealed the following model fit when considering Grade 5 to 7 students: $\chi^{2}(18)=260.11, p<.001$, RMSEA $=.09$, CFI $=.98$, TLI $=.92, \mathrm{SRMR}=.05$. When considering data from Grade 6 to 8 students, the FF-CLPM fit the data well $\left(\chi^{2}(9)=137.16, p<.001\right.$, RMSEA $=.06$, CFI $=.99$, TLI $=.97$, SRMR $\left.=.04\right)$. Importantly, unconstrained FF-CLPMs with three measurement timepoints are saturated $(d f=$ 0 ) and thus fit perfectly, which is why no model fit statistics were computed for these models.

Finally, we inspected model fit statistics of the RI-CLPMs. As displayed in Table 4, these models had a good fit to the data, when considering Grade 5-Grade 7 data (RI-CLPM G56/G67: $\left.\chi^{2}(3)=11.63, p<.01, \mathrm{RMSEA}=.03, \mathrm{CFI}=.99, \mathrm{TLI}=.99, \mathrm{SRMR}=.01\right)$ as well as when considering Grade 6 to Grade 8 data (RI-CLPM G67/G78: $\chi^{2}(3)=13.77, p<.01$, RMSEA $=.03, \mathrm{CFI}=.99, \mathrm{TLI}=.99, \mathrm{SRMR}=.01)$. Similarly, as visible in Table 4, RI-CLPMs with equality constraints also showed a good fit to the data. 
Autoregressive and Cross-Lagged Coefficients. In the next step, we inspected the different autoregressive and cross-lagged coefficients for the models. We first considered Grade 5 to Grade 7 data. As shown in Table 5 and Figure 4, we found substantial autoregressive coefficients in the CLPMs without model constraints for standardized test achievement $(\beta=.75, p<.001)$, for self-concept $(\beta=.55, p<.001)$, and for grades $(\beta=.50, p$ $<.001)$. These findings therefore mimic the correlational findings, as outlined above. Regarding opposing constructs, we found statistically significant associations between all constructs $(p<.05)$ but one: the association between prior self-concept in mathematics in Grade 6 and standardized test achievement in Grade 7 did not reach statistical significance ( $\beta$ $=.02, p=.226)$. Results for CLPMs with time constraints were similar to these prior results except that the relation between prior self-concept and subsequent standardized test achievement also reached statistical significance $(\beta=.04, p=.004)$. These findings from CLPMs are in line with the large amount of prior studies that have found evidence in favor of the reciprocal effects model in which prior self-concept is a predictor of subsequent achievement (grades in particular) and prior achievement is positively associated with subsequent self-concept in mathematics (e.g., Ehm et al., 2019; Marsh \& Craven, 2006).

Results for the FF-CLPMs were quite comparable to the results of the CLPMs with two exceptions: the association between grades in Grade 6 and test scores in Grade 7 (see Figure 4) was not statistically significant $(\beta=.03, p=.319)$, similar to the relation between grades in Grade 6 and self-concept in Grade $7(\beta=.04, p=.096)$. In contrast to these findings, the constrained FF-CLPM results were largely comparable to those found in the constrained CLPM.

Following this, we inspected results for the RI-CLPMs. Prior studies found differences between results from traditional CLPMs and RI-CLPMs (Bailey et al., 2020; Burns et al., 2020; Ehm et al., 2019) in terms of attenuating, directional changing, or even 
vanishing associations. Our findings are in line with these prior findings and suggest that of the six different cross-lagged coefficients, only the association between prior self-concept and subsequent grades remained statistically significant $(\beta=.23, p<.001)$ in the unconstrained model, whereas in the respective FF-CLPM this number amounted to 3 and in the respective CLPM to 5. However, when considering results of the constrained RI-CLPM, our findings are much more in line with results from the CLPM and the FF-CLPM in that both prior grades were found to predict subsequent self-concept $(\beta=.14, p<.001)$ and prior selfconcept was found to predict subsequent grades $(\beta=.24, p<.001$; see Table 5$)$.

Comparison of Estimates Across Grades. When comparing our findings for the Grade 5 to Grade 7 models with results for the Grade 6 to Grade 8 models, we found large similarities, with few exceptions. Most important for the focus of this study, the association between grades and self-concept was not statistically significant for the RI-CLPM ${ }_{\mathrm{G} 678}$ model, whereas this association was found when considering Grade 5 to Grade 7 data (i.e., in the RICLPM $_{\mathrm{G} 567}$ model).

To sum up, results from the three different models are largely in line with findings from prior studies on this topic (Burns et al., 2020; Ehm et al., 2019). They show that whereas the CLPM and the FF-CLPM tend to produce evidence in favor of a reciprocal effects model between grades and self-concept and, depending on the model, also for standardized test achievement and self-concept, this finding is less consistent when using RICLPMs. Regarding cross-lagged coefficients, with the exception of the RI-CLPM ${ }_{\mathrm{G} 567}$, only the association between prior self-concept and subsequent grades consistently reached statistical significance, which would produce evidence in favor of a self-enhancement model. However, it is important to keep in mind the interpretational differences when comparing these model results (see Table 2; e.g., Lüdtke \& Robitzsch, 2021; Orth et al., 2021; Usami et al., 2019) 


\section{Results of EB and CBGPS-Weighting}

Balance Before and After Weighting. Finally, we closely inspected the results from the two weighting methods for continuous treatment variables, namely EB and CBGPS. To this end, we first checked covariate balance for the different treatment conditions. Figure 3 shows the treatment covariate correlation in the adjusted and unadjusted samples for all covariates considered, separately for EB (A-C) and CBGPS-weighting (D-F) and for the three different weighting variables. As can be seen, correlations were substantial before weighting, particularly for matching constructs (e.g., self-concept at the second and first measurement occasions), but also for other variables such as cognitive abilities. For instance, for standardized test achievement before weighting, treatment-covariate correlations ranged from $r=-.44$ to .83 across covariates. After weighting, these correlations reduced to zero for all covariates when using EB (see Figure 3 (A)). This suggests that weights were estimated in such a way that covariates were perfectly balanced across different levels of the treatment variable and constitutes a specific feature of EB (e.g., Zhao \& Percival, 2017). Similar results were found for the other weighting variables (panel B-C) when EB was applied. With regard to CBGPS-weighting, covariate balance substantially improved and amounted to $r<.1$ for the large majority of variables. However, balance was not as good as for EB, which is evident from panel D-F in Figure 3. For instance, for standardized test achievement, balance after weighting improved with an average absolute correlation of $M=0.18$ before and $M=0.05$ after adjustment for CBGPS. Highest correlations after weighting were found for matching constructs (e.g., for achievement), whereas correlations for all other constructs were substantially smaller in the large majority of cases below $r=.1$. As outlined above, these remaining imbalances were addressed by including the covariates again in the estimating step, which is commonly referred to as doubly robust estimation (Schafer \& Kang, 2008). 
Effects of Self-Concept on Grades and Vice Versa. The results for EB displayed in

Table 5 (also see Figure 4) suggest that prior grades had a positive effect on subsequent selfconcept (all $\beta=.11$, all $p \leq .001)$ and self-concept had a positive effect on grades $(\beta=.22 / 23$, all $p<.001$; results without trimming before and trimmed results after the slash). When applying CBGPS-weighting and using the resulting trimmed weights, this finding could be replicated for the effect of prior grades on self-concept $(\beta=.12, p=.002)$ and prior selfconcept on grades $(\beta=.21 / .22$, all $p \leq .001)$. It is important to note that in very few cases, very large weights were estimated when using CBGPS. This makes the solution with $1 \%$ trimmed weights more reliable to use in the case of CBGPS-weighting (Thoemmes \& Ong, 2016). For EB, no such extreme weights were computed.

Effects of Self-Concept on Standardized Test Achievement and Vice Versa. Next, we more closely examined results for the estimates of the effects of standardized test achievement on self-concept and vice versa. Here, we found statistically significant coefficients for the effect of math self-concept on subsequent standardized test achievement, which ranged from $\beta=.06$ to .07 (all $p \leq .01$ ). However, the reverse effect of test achievement on math self-concept did not reach statistical significance (all $p>.05$ ).

Comparison of Effect Estimates. When comparing estimates of the effects for the respective Grade 6 variables on Grade 7 with those resulting from estimating Grade 7 variables on G8 (see EB and CBGPS results in Table 5 and Table 6), results were fairly similar. When estimating the Grade 7 on Grade 8 effect, self-concept had a statistically significant effect on grades, ranging from $\beta=.14$ to .17 (all $p<.001$ ), and grades had a statistically significant effect on self-concept, ranging from $\beta=.15$ to .17 (all $p<.001$ ). In addition, the effect of test achievement on self-concept was statistically significant for all weighting methods (all $\beta=.17$, all $p<.05$ ); however, the reverse effect did not reach statistical significance in any of the models (all $p>.05$ ). 
In sum, results from the weighting methods produced evidence in favor of the REM because we consistently found positive effects of math self-concept on grades and vice versa with the exception of one of eight models, namely the CBGPS $_{\mathrm{G} 67}$ in which we found only a one-sided statistically significant effect of grades on self-concept. Effects of standardized test achievement on self-concept and vice versa were consistent within but less consistent across the two grade groups G5-G7 and G6-G8 (see Table 5 and Table 6). Depending on the grade group, we found evidence either in favor of the self- or the skill-enhancement model.

\section{Discussion}

In this substantive-methodological synergy, we investigated the REM using five different approaches: the CLPM, the FF-CLPM, the RI-CLPM, EB, and CBGPS. Prior research has suggested that the RI-CLPM might be superior to traditional CLPMs in identifying causal effects because it relaxes some of the strong assumptions of CLPMs by controlling for time-stable differences between persons (e.g., Hamaker et al., 2015; Usami, 2021). In contrast, other studies have questioned the validity of this argument by underscoring interpretational differences and suggesting that the CLPM and particularly the FF-CLPM are more useful for addressing causal questions with rather large measurement timepoint intervals, as in our study with one-year lags (Lüdtke \& Robitzsch, 2021; Orth et al., 2021). In addition, researchers have also proposed to make use of more recently developed weighting methods to investigate reciprocal causal effects through unidirectional causal effect estimates (Usami et al., 2019), and we have highlighted that these methods might be promising in terms of satisfying required assumptions for causal interpretations (see Table 1), in particular when a large number of validly measured potential confounders can be included in the analyses as in the present study. This study aimed at comparing results of the five different proposed models/methods. 
In this study, we proposed two sets of overarching questions: First, what are the assumptions for causal inference made by weighting methods and how likely are they satisfied when investigating reciprocal effects between self-concept and achievement? Second, is there evidence for reciprocal effects of academic self-concept and achievement when using these methods for causal inference and how do results from traditional and new methods compare to one another?

Regarding the first question, we have provided insights into one of several options (continuous treatment variable weighting) which goes along with the advantage of making assumptions related to causality more plausible. This is particularly evident for the strong ignorability assumption, which is unlikely to hold in scenarios in which only two or three variables are considered over time when estimating CLPMs (e.g., Usami et al., 2019). As outlined, we have shown that weighting approaches easily allow the inclusion of a broad set of potential time-stable and time-varying confounders and to assess and potentially optimize covariate balance before estimating actual treatment effects. Therefore, the application of these methods for investigating reciprocal associations via unidirectional causal effect estimates provides a promising extension to prior strategies utilized in the field of educational psychology (Usami et al., 2019).

Regarding the second question, CLPMs, FF-CLPMs, and weighting methods all painted a fairly similar overarching picture and provided evidence in favor of an REM for self-concept and grades, which is largely in line with prior studies (e.g., Arens et al., 2017; Ehm et al., 2019; Marsh \& Craven, 2006). Interestingly, results were less consistent when considering standardized test achievement, which has been noted in prior literature (Marsh et al., 2005; Wu et al., 2021), and might result from differences in the stakes of the test versus grades (i.e., grades are high stakes, whereas tests are low stakes) or from the fact that students were not aware of their test results because no feedback was provided at the individual 
student level in the TRAIN study. Support for this assumption can be found in Table 3. As visible, grades and self-concept were more strongly associated compared to achievement tests and self-concept. In addition, the TRAIN study focused low track and intermediate track school students, which might have further contributed to these findings: That is, prior research has found the association between self-concept and test achievement to be considerably lower in low tracks compared to academic tracks (e.g., Penk et al., 2014).

When comparing results from the RI-CLPMs with those from the other models/methods, similarities in findings reduced: We found consistent evidence only for the association between prior self-concept and subsequent grades, whereas the reverse association was statistically significant only in one model (RI-CLPM ${ }_{\mathrm{G} 567)}$. This finding reflects results from prior studies, which also reported differences between coefficients from CLPMs, FF-CLPMs, and RI-CLPMs. In these studies, coefficients typically changed in their size and direction when applying RI-CLPMs (e.g., Bailey et al., 2020; Burns et al., 2020). For example, Ehm et al. (2019) found cross-lagged coefficients not to be statistically significant anymore, neither for grades nor for standardized test achievement when analyzed with RICLPMs. Notably, as outlined in Table 2 and mentioned in prior studies (Lüdtke \& Robitzsch, 2021; Orth et al., 2021), it is important to recall that coefficients from the RI-CLPMs have a different meaning than those from the other models/methods and that they redefine the causal cross-lagged effect. RI-CLPM's autoregressive and cross-lagged coefficients represent associations between temporal deviations from individuals' average scores (within-person associations), whereas CLPMs, FF-CLPMs, and weighting approaches all follow a selectionon-observable strategy and share a similar interpretation with average increases or decreases based on individuals' prior scores relative to others' (between-person associations). This is important to keep in mind when comparing the different coefficients. If cross-lagged coefficients from RI-CLPMs and CLPMs were comparable, this would suggest that states 
(i.e., temporal deviations from the trait level) are associated to one another in a similar vein as coefficients between mixtures of states and traits. This could occur if, for instance, the random intercepts in the RI-CLPM have zero variance because no stable trait factor exists. Yet, it is unclear if and when this constitutes a reasonable assumption. Although both approaches might be able to identify causal effects in theory under specific assumptions (i.e., within person and between person causal effects; e.g., Gische et al., 2021; Usami et al., 2019; Voelkle et al., 2018), suggestions about when to choose a specific model over another one has just emerged in the respective literature (e.g., Lüdtke \& Robitzsch, 2021; Orth et al., 2021). This shows that how causal a cross-lagged effect is clearly depends on the alignment of the structural causal model and the chosen statistical model.

\section{Limitations}

There are several limitations, which should be mentioned when interpreting the results of our study. First, in this article, we showed that investigating reciprocal relations between variables using weighting methods might constitute a promising alternative approach, which more likely satisfies core assumptions of causality (e.g., the strong ignorability assumption) and is able to estimate autoregressive and cross-lagged effects that are in focus of many studies in educational psychology. However, we also identified some challenges for the application of these methods. For instance, covariate balance of different weighting methods (i.e., EB and CBGPS-weighting) differed to some extent. In line with prior research, we found that EB leads to perfect treatment-covariate balance (Zhao \& Percival, 2017), whereas CBGPS-weighting substantially improved balance but was still not perfect, making the strong ignorability assumption less plausible compared to EB. In order to make the results comparable across the two methods, we decided to use an identical set of covariates when applying EB and CBGPS, which we derived based on prior theoretical considerations. However, following classical recommendations (Thoemmes \& Kim, 2011), researchers 
should be warned because they might fall into a "propensity score tautology" (Imai et al., 2008) when other weighting approaches than EB are applied and thus are advised to respecify the selection model repeatedly by adding and dropping covariates to receive adequate balance, which can get tedious and can lead to even less balance (e.g., Hainmueller, 2012).

Second, as is visible from Usami et al. (2019), a broad variety of different models exist, all of which could be reasonably used to investigate reciprocal relations between selfconcept and achievement. In this study, we have focused on three types of longitudinal models from recent research, the CLPM, the FF-CLPM, and the RI-CLPM and ignored other models, which have gained attention in more recent research (e.g., Núñez-Regueiro et al., 2021). Two arguments guided our decision to do so: First, the models that we compared in this study are most prominently used when investigating questions related to reciprocal associations between achievement and self-concept. This is visible from a broad set of prior studies and meta analyses (e.g., Arens et al., 2017; Burns et al., 2020; Ehm et al., 2019; Hamaker et al., 2015; Huang, 2011; Lüdtke \& Robitzsch, 2021; Marsh \& Craven, 2006; Mulder \& Hamaker, 2021; Preckel et al., 2017; Sewasew et al., 2018). Second, the interpretation of autoregressive and cross-lagged coefficients differs across models. This was already noted when comparing the RI-CLPM results with results from the other models/methods in this study, but differences between models become even more visible when comparing some of the other models, for instance the LCM-SR (also referred to as RCCLPM; Núñez-Regueiro et al., 2021 ) with the FF-CLPM (e.g., Orth et al., 2021). Even more worrying, as more thoroughly outlined by Usami et al. (2019), if dynamics reflect relations after controlling for developmental changes, such "new" models might throw "the baby out with the bathwater" (p. 649) because if relations between developmental processes are of interest, these move into the slope factor of such models. This has also led to discussions in the methodological literature on whether random slopes should generally be included in 
CLPMs or not (e.g., Berry \& Willoughby, 2017; Curran et al., 2014; Núñez-Regueiro et al., 2021; Zyphur et al., 2020). Therefore, before applying these models to the debate about reciprocal causal effects, we feel that more research would be required to thoroughly outline respective assumptions and underlying developmental theories.

\section{Implications and Future Prospects}

The results of our substantive-methodological synergy have important implications. First, when inspecting and comparing assumptions of the different structural causal models (see Figure 1), it seems unlikely that we are recovering true causal cross-lagged effects in many application contexts in educational psychology using CLPMs, FF-CLPMs, or RICLPMs. This was highlighted in prior research (e.g., Usami et al., 2015; Usami et al., 2019) and mainly results from how these models are currently applied. Typically, only two or three endogenous variables are considered repeatedly over time, and therefore, particularly the strong ignorability assumption seems implausible to be satisfied. As this is not an inherent limitation of the statistical models, it seems important to invest time in reconsidering current standards when using these models. As one example, it seems relatively easy to extend traditional CLPMs and FF-CLPMs by including additional time-stable and time-varying covariates (e.g., Usami et al., 2019) in order to increase the likelihood of the strong ignorabiltiy assumption. However, this is seldom done in practice. Also, models might quickly get overly complex and struggle to converge when adding large sets of covariates in a structural equation framework. In contrast, weighting approaches might be able to better satisfy requirements to estimate causal cross-lagged effects, particularly because they simplify to consider large sets of observed covariates and because they require researchers to more thoroughly investigate and potentially optimize covariate balance.

From a more substantial perspective related to the REM, although coefficients vary across the different models/methods, all models (besides the RI-CLPM) produced evidence in 
favor of the REM. Thus, these results suggest that CLPMs and FF-CLPMs might actually not perform as badly in empirical settings as suggested in prior methodological studies, and by the violation of the strong ignorability assumption outlined above (e.g., Bailey et al., 2020).

Finally, this study shows that more studies are needed to clarify which causal effects different theoretical models discuss/define and which of these effects different statistical models actually estimate. This might include simulation studies but also theoretical work that helps applied researchers to make better decisions regarding assumptions about the underlying structural causal model, which can then be transferred into adequate statistical models. In addition, there is a very lively discussion going on about whether within- or between-person coefficients are the "holy grail of longitudinal SEM" (i.e., within or between effects or mixtures of both of these effects), how they should be estimated (Voelkle et al., 2018), how they are defined from a causal perspective, and what they actually mean for theory and practice. At the moment, it seems that the methodological debate about the "right model" (either RI-CLPM or the CLPM/FF-CLPM) has left applied researchers and even methodologists with bemusement on what model to choose for what kind of research question and data situation. Addressing this gap in the literature will be an important task for future research.

\section{Summary}

This substantive-methodological synergy investigated the REM and aimed at contrasting traditional and more recently developed methods to investigate reciprocal effects of students' academic self-concept and achievement, one of the most prominent models in educational psychology (Wu et al., 2021). In this study, we investigated how different models/methods satisfy requirements to estimate causal cross-lagged parameters: the CLPM, the FF-CLPM, the RI-CLPM, and weighting techniques to estimate causal effects of continuous treatment variables (Fong et al., 2018; Hainmueller, 2012; Tübbicke, 2021). 
CLPMs, FF-CLPMs, and results from weighting methods produced evidence in favor of the REM, whereas in line with findings from prior studies(e.g., Bailey et al., 2020; Burns et al., 2020; Ehm et al., 2019), results for the RI-CLPM were mixed. 


\section{References}

Arens, A. K., Marsh, H. W., Pekrun, R., Lichtenfeld, S., Murayama, K., \& vom Hofe, R. (2017). Math self-concept, grades, and achievement test scores: Long-term reciprocal effects across five waves and three achievement tracks. Journal of Educational Psychology, 109(5), 621-634. https://doi.org/10.1037/edu0000163

Bailey, D. H., Oh, Y., Farkas, G., Morgan, P., \& Hillemeier, M. (2020). Reciprocal effects of reading and mathematics? Beyond the cross-lagged panel model. Developmental Psychology, 56(5), 912-921. https://doi.org/10.1037/dev0000902

Baumert, J., Roeder, P. M., Gruehn, S., Heyn, S., Köller, O., Rimmele, R., Schnabel, K. U., \& Seipp, B. (1996). Bildungsverläufe und psychosoziale Entwicklung im Jugendalter (BIJU). Waxmann.

Berry, D., \& Willoughby, M. T. (2017). On the practical interpretability of cross-lagged panel models: Rethinking a developmental workhorse. Child Development, 88(4), 11861206. https://doi.org/10.1111/cdev.12660

Brunner, M., Keller, U., Dierendonck, C., Reichert, M., Ugen, S., Fischbach, A., \& Martin, R. (2010). The structure of academic self-concepts revisited: The nested Marsh/Shavelson model. Journal of Educational Psychology, 102(4), 964-981. https://doi.org/10.1037/a0019644

Burns, R. A., Crisp, D. A., \& Burns, R. B. (2020). Re-examining the reciprocal effects model of self-concept, self-efficacy, and academic achievement in a comparison of the Cross-Lagged Panel and Random-Intercept Cross-Lagged Panel frameworks. British Journal of Educational Psychology, 90(1), 77-91.

https://doi.org/10.1111/bjep.12265 
Calsyn, R. J., \& Kenny, D. A. (1977). Self-concept of ability and perceived evaluation of others: Cause or effect of academic achievement? Journal of Educational Psychology, 69(2), 136-145. https://doi.org/10.1037/0022-0663.69.2.136

Chmielewski, A. K., Dumont, H., \& Trautwein, U. (2013). Tracking effects depend on tracking type. American Educational Research Journal, 50(5), 925-957. https://doi.org/10.3102/0002831213489843

Cole, S. R., \& Hernán, M. A [Miguel A.] (2008). Constructing inverse probability weights for marginal structural models. American Journal of Epidemiology, 168(6), 656-664. https://doi.org/10.1093/aje/kwn164

Cunningham, S. (2021). Causal inference: The mixtape. Yale University Press.

Curran, P. J., Howard, A. L., Bainter, S. A., Lane, S. T., \& McGinley, J. S. (2014). The separation of between-person and within-person components of individual change over time: A latent curve model with structured residuals. Journal of Consulting and Clinical Psychology, 82(5), 879-894. https://doi.org/10.1037/a0035297

Ehm, J.-H., Hasselhorn, M., \& Schmiedek, F. (2019). Analyzing the developmental relation of academic self-concept and achievement in elementary school children: Alternative models point to different results. Developmental Psychology, 55(11), 2336-2351. https://doi.org/10.1037/dev0000796

Fong, C., Hazlett, C., \& Imai, K. (2018). Covariate balancing propensity score for a continuous treatment: Application to the efficacy of political advertisements. The Annals of Applied Statistics, 12(1), 156-177. https://doi.org/10.1214/17-AOAS1101

Fong, C., Ratkovic, M., Imai, K., Hazlett, C., Yang, X., \& Peng, S. (2021). Package CBPS: Covariate balancing propensity score. https://CRAN.R-project.org/package=CBPS

Gische, C., West, S. G., \& Voelkle, M. C. (2021). Forecasting causal effects of interventions versus predicting future outcomes. Structural Equation Modeling: A 
Multidisciplinary Journal, 28(3), 475-492.

https://doi.org/10.1080/10705511.2020.1780598

Greifer, N. (2021a). Package cobalt: Covariate balance tables and plots. https://cran.rproject.org/web/packages/cobalt/cobalt.pdf

Greifer, N. (2021b). Package WeightIt: Matching and weighting multiply imputed datasets. https://cran.r-project.org/web/packages/WeightIt/WeightIt.pdf

Hainmueller, J. (2012). Entropy balancing for causal effects: A multivariate reweighting method to produce balanced samples in observational studies. Political Analysis, 20(1), 25-46. https://doi.org/10.1093/pan/mpr025

Hallquist, M. N., \& Wiley, J. F. (2018). Mplusautomation: An R package for facilitating large-scale latent variable analyses in Mplus. Structural Equation Modeling: A Multidisciplinary Journal, 25(4), 621-638. https://doi.org/10.1080/10705511.2017.1402334

Hamaker, E. L., Kuiper, R. M., \& Grasman, R. P. P. P. (2015). A critique of the cross-lagged panel model. Psychological Methods, 20(1), 102-116. https://doi.org/10.1037/a0038889

Hamaker, E. L., \& Muthén, B. (2020). The fixed versus random effects debate and how it relates to centering in multilevel modeling. Psychological Methods, 25(3), 365-379. https://doi.org/10.1037/met0000239

Helmke, A., \& van Aken, M. A. G. (1995). The causal ordering of academic achievement and self-concept of ability during elementary school: A longitudinal study. Journal of Educational Psychology, 87(4), 624-637. https://doi.org/10.1037/00220663.87.4.624

Holland, P. W. (1986). Statistics and causal inference. Journal of the American Statistical Association, 81(396), 945. https://doi.org/10.2307/2289064 
Hu, L., \& Bentler, P. M. (1999). Cutoff criteria for fit indexes in covariance structure analysis: Conventional criteria versus new alternatives. Structural Equation Modeling: A Multidisciplinary Journal, 6(1), 1-55. https://doi.org/10.1080/10705519909540118

Huang, C. (2011). Self-concept and academic achievement: A meta-analysis of longitudinal relations. Journal of School Psychology, 49(5), 505-528. https://doi.org/10.1016/j.jsp.2011.07.001

Hübner, N., Spengler, M., Nagengast, B., Borghans, L., Schils, T., \& Trautwein, U. (2021). When academic achievement (also) reflects personality: Using the personalityachievement saturation hypothesis (PASH) to explain differential associations between achievement measures and personality traits. Journal of Educational Psychology. Advance online publication. https://doi.org/10.1037/edu0000571

Hübner, N., Trautwein, U., \& Nagengast, B. (2021). Should I stay or should I go? Predictors and effects of studying abroad during high school. Learning and Instruction, 71, 101398. https://doi.org/10.1016/j.learninstruc.2020.101398

Hübner, N., Wille, E., Cambria, J., Oschatz, K., Nagengast, B., \& Trautwein, U. (2017). Maximizing gender equality by minimizing course choice options? Effects of obligatory coursework in math on gender differences in STEM. Journal of Educational Psychology, 109(7), 993-1009. https://doi.org/10.1037/edu0000183

Imai, K., King, G., \& Stuart, E. A. (2008). Misunderstandings between experimentalists and observationalists about causal inference. Journal of the Royal Statistical Society: Series a (Statistics in Society), 171(2), 481-502. https://doi.org/10.1111/j.1467985X.2007.00527.x

Imai, K., \& Ratkovic, M. (2014). Covariate balancing propensity score. J. R. Stat. Soc. B, 76(1), 243-263. https://doi.org/10.1111/rssb.12027 
Jonkmann, K., Rose, N., \& Trautwein, U. (Eds.). (2013). Tradition und Innovation: Entwicklungsverläufe an Haupt- und Realschulen in Baden-Württemberg und Mittelschulen in Sachsen: Abschlussbericht für die Länder Baden-Württemberg und Sachsen [Tradition and Innovation: Student development at low- and intermediatetrack schools in Baden-Württemberg and comprehensive track schools in Saxony]. Hector Research Institute of Education Sciences and Psychology.

Kang, J., Chan, W., Kim, M.-O., \& Steiner, P. M. (2016). Practice of causal inference with the propensity of being zero or one: Assessing the effect of arbitrary cutoffs of propensity scores. Communications for Statistical Applications and Methods, 23(1), 1-20. https://doi.org/10.5351/CSAM.2016.23.1.001

Lehmann, R. H., \& Lenkeit, J. (2008). ELEMENT. Erhebung zum Lese- und Mathematikverständnis - Entwicklungen in den Jahrgangsstufen 4 bis 6 in Berlin. Abschlussbericht über die Untersuchungen 2003, 2004 und 2005 an Berliner Grundschulen und grundständigen Gymnasien [ELEMENT. Survey for reading and mathematics literacy. Development in grades 4 to 6 in Berlin. Final research report on the surveys in 2003, 2004, and 2005 in primary schools and undergraduate academic tracks in Berlin]. Humboldt-Universität zu Berlin.

Leyrat, C., Seaman, S. R., White, I. R., Douglas, I., Smeeth, L., Kim, J., Resche-Rigon, M., Carpenter, J. R., \& Williamson, E. J. (2019). Propensity score analysis with partially observed covariates: How should multiple imputation be used? Statistical Methods in Medical Research, 28(1), 3-19. https://doi.org/10.1177/0962280217713032.

Lüdtke, O., \& Robitzsch, A. (2021). A critique of the random intercept cross-lagged panel model. https://doi.org/10.31234/osf.io/6f85c

Lumley, T. (2018). Package 'survey'. https://cran.rproject.org/web/packages/survey/survey.pdf 
Marsh, H. W. (1990a). Causal ordering of academic self-concept and academic achievement: A multiwave, longitudinal panel analysis. Journal of Educational Psychology, 82(4), 646-656. https://doi.org/10.1037/0022-0663.82.4.646

Marsh, H. W. (1990b). The structure of academic self-concept: The Marsh/Shavelson model. Journal of Educational Psychology, 82(4), 623-636. https://doi.org/10.1037/00220663.82 .4 .623

Marsh, H. W. (1992). Self description questionnaire (SDQ) III: A theoretical and empirical basis for the Measurement of multiple dimensions of late adolescent self-concept: A test manual and a research monograph.

Marsh, H. W., \& Craven, R. G. (2006). Reciprocal effects of self-concept and performance from a multidimensional perspective: Beyond seductive pleasure and unidimensional perspectives. Perspectives on Psychological Science, 1(2), 133-163. https://doi.org/10.1111/j.1745-6916.2006.00010.x

Marsh, H. W., \& Hau, K.-T. (2007). Applications of latent-variable models in educational psychology: The need for methodological-substantive synergies. Contemporary Educational Psychology, 32(1), 151-170. https://doi.org/10.1016/j.cedpsych.2006.10.008

Marsh, H. W., \& Martin, A. J. (2011). Academic self-concept and academic achievement: Relations and causal ordering. British Journal of Educational Psychology, 81(Pt 1), 59-77. https://doi.org/10.1348/000709910X503501

Marsh, H. W., Martin, A. J., Yeung, A. S., \& Craven, R. (2016). Competence selfperceptions. In A. J. Elliot, C. S. Dweck, \& D. Yeager (Eds.), Handbook of competence and motivation (pp. 85-115). Guilford Press.

Marsh, H. W., Trautwein, U., Lüdtke, O., Köller, O., \& Baumert, J. (2005). Academic selfconcept, interest, grades, and standardized test scores: Reciprocal effects models of 
causal ordering. Child Development, 76(2), 397-416. https://doi.org/10.1111/j.14678624.2005.00853.x.

Möller, J., Pohlmann, B., Köller, O., \& Marsh, H. W. (2009). A meta-analytic path analysis of the internal/external frame of reference model of academic achievement and academic self-concept. Review of Educational Research, 79(3), 1129-1167. https://doi.org/10.3102/0034654309337522

Möller, J., Zitzmann, S., Helm, F., Machts, N., \& Wolff, F. (2020). A meta-analysis of relations between achievement and self-concept. Review of Educational Research, 90(3), 376-419. https://doi.org/10.3102/0034654320919354

Mulder, J. D., \& Hamaker, E. L. (2021). Three extensions of the random intercept crosslagged panel model. Structural Equation Modeling: A Multidisciplinary Journal, 28(4), 638-648. https://doi.org/10.1080/10705511.2020.1784738

Muthén, L. K., \& Muthén, B. O. (1998-2017). Mplus user's guide. Eighth Edition. Muthén \& Muthén.

Núñez-Regueiro, F., Juhel, J., Bressoux, P., \& Nurra, C. (2021). Identifying reciprocities in school motivation research: A review of issues and solutions associated with crosslagged effects models. Journal of Educational Psychology. Advance online publication. https://doi.org/10.1037/edu0000700

O'Mara, A. J., Marsh, H. W., Craven, R. G., \& Debus, R. L. (2006). Do self-concept interventions make a difference? A synergistic blend of construct validation and meta-analysis. Educational Psychologist, 41(3), 181-206. https://doi.org/10.1207/s15326985ep4103_4

Orth, U., Clark, D. A., Donnellan, M. B., \& Robins, R. W. (2021). Testing prospective effects in longitudinal research: Comparing seven competing cross-lagged models. Journal 
of Personality and Social Psychology, 120(4), 1013-1034. https://doi.org/10.1037/pspp0000358

Pearl, J. (2009). Causality: Models, reasoning, and inference (2nd ed.). Cambridge Univ. Press.

Pearl, J., Glymour, M., \& Jewell, N. P. (2016). Causal inference in statistics: A primer. Wiley. http://lib.myilibrary.com/detail.asp?ID=895561

Penk, C., Pöhlmann, C., \& Roppelt, A. (2014). The role of test-taking motivation for students' performance in low-stakes assessments: an investigation of school-trackspecific differences. Large-Scale Assessments in Education, 2(1), 271. https://doi.org/10.1186/s40536-014-0005-4

Pinxten, M., Fraine, B. de, van Damme, J., \& D'Haenens, E. (2010). Causal ordering of academic self-concept and achievement: Effects of type of achievement measure. British Journal of Educational Psychology, 80(Pt 4), 689-709. https://doi.org/10.1348/000709910X493071

Pishgar, F., Greifer, N., Leyrat, C., \& Stuart, E. (2020). Package MatchThem: Matching and weighting multiply imputed datasets. https://cran.rproject.org/web/packages/MatchThem/MatchThem.pdf

Pishgar, F., Greifer, N., Leyrat, C., \& Stuart, E. (2021). MatchThem: Matching and Weighting after Multiple Imputation. The R Journal. https://journal.rproject.org/archive/2021/RJ-2021-073/index.html

Preckel, F., Schmidt, I., Stumpf, E., Motschenbacher, M., Vogl, K., \& Schneider, W. (2017). A test of the reciprocal-effects model of academic achievement and academic selfconcept in regular classes and special classes for the gifted. Gifted Child Quarterly, 61(2), 103-116. https://doi.org/10.1177/0016986216687824 
R Development Core Team. (2021). $R$ : A language and environment for statistical computing. R Foundation for Statistical Computing. http://www.R-project.org

Rehkopf, D. H., Glymour, M. M., \& Osypuk, T. L. (2016). The consistency assumption for causal inference in social epidemiology: When a rose is not a rose. Current Epidemiology Reports, 3(1), 63-71. https://doi.org/10.1007/s40471-016-0069-5

Robins, J. M., Hernán, M. A [M. A.], \& Brumback, B. (2000). Marginal structural models and causal inference in epidemiology. Epidemiology, 11(5), 550-560. https://doi.org/10.1097/00001648-200009000-00011

Robitzsch, A., Grund, S., \& Henke, T. (2021). Package 'miceadds'. https://cran.rproject.org/web/packages/miceadds/miceadds.pdf

Rogosa, D. (1980). A critique of cross-lagged correlation. Psychological Bulletin, 88(2), 245-258. https://doi.org/10.1037/0033-2909.88.2.245

Rose, N., Jonkmann, K., Hübner, N., Sälzer, C., Lüdtke, O., \& Nagy, G. (2013). Durchführung und methodische Grundlagen der TRAIN-Studie [Implementation and methodological foundations of the TRAIN study]. In K. Jonkmann, N. Rose, \& U. Trautwein (Eds.), Tradition und Innovation: Entwicklungsverläufe an Haupt- und Realschulen in Baden-Württemberg und Mittelschulen in Sachsen: Abschlussbericht für die Länder Baden-Württemberg und Sachsen (pp. 77-102). Hector Research Institute of Education Sciences and Psychology.

Rosenbaum, P. R., \& Rubin, D. B. (1983). The central role of the propensity score in observational studies for causal effects. Biometrika, 70(1), 41. https://doi.org/10.2307/2335942

Rubin, D. B. (1974). Estimating causal effects of treatments in randomized and nonrandomized studies. Journal of Educational Psychology, 66(5), 688-701. https://doi.org/10.1037/h0037350 
Rubin, D. B. (1987). Multiple imputation for nonresponse in surveys. Wiley.

Rubin, D. B. (2004). Teaching statistical inference for causal effects in experiments and observational studies. Journal of Educational and Behavioral Statistics, 29(3), 343367. https://doi.org/10.3102/10769986029003343

Schafer, J. L., \& Kang, J. (2008). Average causal effects from nonrandomized studies: A practical guide and simulated example. Psychological Methods, 13(4), 279-313. https://doi.org/10.1037/a0014268

Schwanzer, A. D., Trautwein, U., Lüdtke, O., \& Sydow, H. (2005). Entwicklung eines Instruments zur Erfassung des Selbstkonzepts junger Erwachsener. Diagnostica, 51(4), 183-194. https://doi.org/10.1026/0012-1924.51.4.183

Seaton, M., Marsh, H. W., Parker, P. D., Craven, R. G., \& Yeung, A. S. (2015). The reciprocal effects model revisited. Gifted Child Quarterly, 59(3), 143-156. https://doi.org/10.1177/0016986215583870

Sewasew, D., Schroeders, U., Schiefer, I. M., Weirich, S., \& Artelt, C. (2018). Development of sex differences in math achievement, self-concept, and interest from grade 5 to 7. Contemporary Educational Psychology, 54, 55-65. https://doi.org/10.1016/j.cedpsych.2018.05.003

Shadish, W. R. (2010). Campbell and Rubin: A primer and comparison of their approaches to causal inference in field settings. Psychological Methods, 15(1), 3-17. https://doi.org/10.1037/a0015916

Shavelson, R. J., Hubner, J. J., \& Stanton, G. C. (1976). Self-concept: Validation of construct interpretations. Review of Educational Research, 46(3), 407-441. https://doi.org/10.3102/00346543046003407 
Sirin, S. R. (2005). Socioeconomic status and academic achievement: A meta-analytic review of research. Review of Educational Research, 75(3), 417-453. https://doi.org/10.3102/00346543075003417

Thoemmes, F., \& Kim, E. S. (2011). A systematic review of propensity score methods in the social sciences. Multivariate Behavioral Research, 46(1), 90-118. https://doi.org/10.1080/00273171.2011.540475

Thoemmes, F., \& Ong, A. D. (2016). A primer on inverse probability of treatment weighting and marginal structural models. Emerging Adulthood, 4(1), 40-59. https://doi.org/10.1177/2167696815621645

Tübbicke, S. (2021). Entropy balancing for continuous treatments. Journal of Econometric Methods. Advance online publication. https://doi.org/10.1515/jem-2021-0002

Uchida, A., Michael, R. B., \& Mori, K. (2018). An Induced Successful Performance Enhances Student Self-Efficacy and Boosts Academic Achievement. AERA Open, 4(4), 233285841880619. https://doi.org/10.1177/2332858418806198

Usami, S. (2021). On the differences between general cross-lagged panel model and randomintercept cross-lagged panel model: Interpretation of cross-lagged parameters and model choice. Structural Equation Modeling: A Multidisciplinary Journal, 28(3), 331-344. https://doi.org/10.1080/10705511.2020.1821690

Usami, S., Hayes, T., \& McArdle, J. J. (2015). On the mathematical relationship between latent change score and autoregressive cross-lagged factor approaches: Cautions for inferring causal relationship between variables. Multivariate Behavioral Research, 50(6), 676-687. https://doi.org/10.1080/00273171.2015.1079696

Usami, S., Murayama, K., \& Hamaker, E. L. (2019). A unified framework of longitudinal models to examine reciprocal relations. Psychological Methods, 24(5), 637-657. https://doi.org/10.1037/met0000210 
Valentine, J. C., DuBois, D. L., \& Cooper, H. (2004). The relation between self-beliefs and academic achievement: A meta-analytic review. Educational Psychologist, 39(2), 111-133. https://doi.org/10.1207/s15326985ep3902

Vanderweele, T. J. (2019). Principles of confounder selection. European Journal of Epidemiology, 34(3), 211-219. https://doi.org/10.1007/s10654-019-00494-6

Vanderweele, T. J., Mathur, M. B., \& Chen, Y. (2020). Outcome-wide longitudinal designs for causal inference: A new template for empirical studies. Statistical Science, 35(3). https://doi.org/10.1214/19-STS728

Voelkle, M. C., Gische, C., Driver, C. C., \& Lindenberger, U. (2018). The role of time in the quest for understanding psychological mechanisms. Multivariate Behavioral Research, 53(6), 782-805. https://doi.org/10.1080/00273171.2018.1496813

Voyer, D., \& Voyer, S. D. (2014). Gender differences in scholastic achievement: A metaanalysis. Psychological Bulletin, 140(4), 1174-1204. https://doi.org/10.1037/a0036620

Watt, H. M., Hyde, J. S., Petersen, J., Morris, Z. A., Rozek, C. S., \& Harackiewicz, J. M. (2017). Mathematics - a critical filter for STEM-related career choices? A longitudinal examination among Australian and U.S. adolescents. Sex Roles, 77(34), 254-271. https://doi.org/10.1007/s11199-016-0711-1

Watt, H. M., Shapka, J. D., Morris, Z. A., Durik, A. M., Keating, D. P., \& Eccles, J. S. (2012). Gendered motivational processes affecting high school mathematics participation, educational aspirations, and career plans: A comparison of samples from Australia, Canada, and the United States. Developmental Psychology, 48(6), 1594-1611. https://doi.org/10.1037/a0027838

West, S. G., \& Thoemmes, F. (2010). Campbell's and Rubin's perspectives on causal inference. Psychological Methods, 15(1), 18-37. https://doi.org/10.1037/a0015917 
Wu, H., Guo, Y., Yang, Y., Le Zhao, \& Guo, C. (2021). A meta-analysis of the longitudinal relationship between academic self-concept and academic achievement. Educational Psychology Review. Advance online publication. https://doi.org/10.1007/s10648021-09600-1

Wylie, R. C. (1979). The Self-Concept: Theory and research on selected topics (2nd ed.). University of Nebraska Press.

Zhao, Q., \& Percival, D. (2017). Entropy balancing is doubly robust. Journal of Causal Inference, 5(1), Article 20160010. https://doi.org/10.1515/jci-2016-0010

Zyphur, M. J., Voelkle, M. C., Tay, L., Allison, P. D., Preacher, K. J., Zhang, Z., Hamaker, E. L., Shamsollahi, A., Pierides, D. C., Koval, P., \& Diener, E. (2020). From data to causes II: Comparing approaches to panel data analysis. Organizational Research Methods, 23(4), 688-716. https://doi.org/10.1177/1094428119847280 


\section{Table 1}

Comparison of Central Assumptions Between Different Methodological Approaches to Estimate Reciprocal Effects of Self-Concept and Achievement

\begin{tabular}{|c|c|c|c|c|}
\hline Assumption/Model & CLPM & FF-CLPM & RI-CLPM & Weighting \\
\hline Consistency & \multicolumn{4}{|c|}{ Individuals' observed outcomes are equal to their potential outcomes, given their history of exposure } \\
\hline $\begin{array}{l}\text { no measurement } \\
\text { error }\end{array}$ & $\begin{array}{l}\text { Realistic if reliable } \\
\text { scales, PVs or latent } \\
\text { variables are used }\end{array}$ & $\begin{array}{l}\text { Realistic if reliable } \\
\text { scales, PVs or latent } \\
\text { variables are used }\end{array}$ & $\begin{array}{l}\text { Realistic if reliable } \\
\text { scales, PVs or latent } \\
\text { variables are used }\end{array}$ & $\begin{array}{l}\text { Realistic if reliable } \\
\text { scales or PVs are used }\end{array}$ \\
\hline $\begin{array}{l}\text { no carryover effects } \\
\text { beyond } \mathrm{t}-1\end{array}$ & Rather unrealistic & $\begin{array}{l}\text { More realistic, as lag- } 2 \\
\text { paths are estimated }\end{array}$ & Rather unrealistic & $\begin{array}{l}\text { More realistic as } \\
\text { multiple variables (and } \\
\text { their pre-measures) can } \\
\text { be considered }\end{array}$ \\
\hline \multirow[t]{2}{*}{ Strong ignorability } & \multicolumn{4}{|c|}{ No unobserved confounding } \\
\hline & $\begin{array}{l}\text { Rather unrealistic as no } \\
\text { covariates are } \\
\text { considered }\end{array}$ & $\begin{array}{l}\text { More realistic as lag- } 2 \\
\text { paths are included }\end{array}$ & $\begin{array}{l}\text { More realistic as time- } \\
\text { invariant between } \\
\text { differences are } \\
\text { controlled }\end{array}$ & $\begin{array}{l}\text { More realistic as many } \\
\text { observed confounders } \\
\text { can be considered easily } \\
\text { (possibly from multiple } \\
\text { timepoints) }\end{array}$ \\
\hline
\end{tabular}

\section{Positivity}

Sufficient overlap in the covariate distribution for different values of the treatment variable

\begin{tabular}{|c|c|c|c|}
\hline $\begin{array}{l}\text { Typically, not } \\
\text { investigated }\end{array}$ & $\begin{array}{l}\text { Typically, not } \\
\text { investigated }\end{array}$ & $\begin{array}{l}\text { Typically, not } \\
\text { investigated but relaxed }\end{array}$ & $\begin{array}{l}\text { Inspection of weights } \\
\text { and estimation of } \\
\text { truncated weights is } \\
\text { possible }\end{array}$ \\
\hline
\end{tabular}

Note. CLPM = Cross-lagged panel model; FF-CLPM = Full-forward CLPM; RI-CLPM = Random intercept CLPM; PV = Plausible value. Please note that, for the sake of clarity, this comparison only considers traditional, most prominently applied versions of different CLPMs in educational psychological research and ignores possible extensions, which are seldom used in practice (e.g., CLPMs or RI-CLPMs with time-varying covariates etc.). 


\section{Table 2}

Interpretations of the Respective Cross-Lagged Coefficients From the CLPM, the FF-CLPM, the RI-CLPM, and Entropy Balancing

\begin{tabular}{|c|c|c|}
\hline Model & $\begin{array}{l}\text { Interpretation of a positive association } \\
\text { Math self-concept } t_{t} \text { on Math achievement_t-1 }\end{array}$ & $\begin{array}{l}\text { Interpretation of a negative association } \\
\text { Math self-concept } t_{t} \text { on Math achievement_t-1 }\end{array}$ \\
\hline CLPM & $\begin{array}{l}\text { Students with a (relative to other students) } \\
\text { higher/lower achievement at timepoint } t \text { - } l \text { have a } \\
\text { (relative to other students) higher/lower self-concept } \\
\text { at timepoint } t \text {. }\end{array}$ & $\begin{array}{l}\text { Students with a (relative to other students) lower/higher } \\
\text { achievement at timepoint } t \text { - } 1 \text { have a (relative to other } \\
\text { students) higher/lower self-concept at timepoint } t \text {. }\end{array}$ \\
\hline FF-CLPM & $\begin{array}{l}\text { Students with a (relative to other students) } \\
\text { higher/lower achievement at timepoint } t-1 \text { have a } \\
\text { (relative to other students) higher/lower self-concept } \\
\text { at timepoint } t \text {, after controlling for their achievement } \\
\text { and self-concept at } t-2 \text {. }\end{array}$ & $\begin{array}{l}\text { Students with a (relative to other students) lower/higher } \\
\text { achievement at timepoint } t-1 \text { have a (relative to other } \\
\text { students) higher/lower self-concept at timepoint } t \text {, after } \\
\text { controlling for their achievement and self-concept at } t-2 \text {. }\end{array}$ \\
\hline RI-CLPM & $\begin{array}{l}\text { Students with a (relative to their average achievement) } \\
\text { higher/lower achievement at timepoint } t \text { - } 1 \text { have a } \\
\text { (relative to their average self-concept) higher/lower } \\
\text { self-concept at timepoint } t \text {. }\end{array}$ & $\begin{array}{l}\text { Students with a (relative to their average achievement) } \\
\text { higher/lower achievement at timepoint } t-l \text { have a (relative to } \\
\text { their average self-concept) lower/higher self-concept at } \\
\text { timepoint } t \text {. }\end{array}$ \\
\hline $\begin{array}{l}\text { Weighting } \\
\text { (e.g., Entropy } \\
\text { Balancing) }\end{array}$ & $\begin{array}{l}\text { Students without any observed differences to other } \\
\text { students at timepoint } t-1 \text {, but with a (relative to other } \\
\text { students) higher/lower achievement at timepoint } t-1 \\
\text { have a (relative to other students) higher/lower self- }\end{array}$ & $\begin{array}{l}\text { Students without any observed differences to other students at } \\
\text { timepoint } t-1 \text {, but with a (relative to other students) } \\
\text { lower/higher achievement at timepoint } t-1 \text { have a (relative to } \\
\text { other students) higher/lower self-concept at timepoint } t \text {. }\end{array}$ \\
\hline
\end{tabular}

Note. The causal interpretation of all models relies on the outlined assumptions in Table 1. If structural causal model (c) from Figure 1 is the true model, coefficients from the weighting approaches most likely fulfill required assumptions (see Table 1) to interpret the coefficients as causal. 


\section{Table 3}

Pooled Correlations, Means, and Standard Deviations Across 20 Imputed Data Sets for Math Self-Concept, Test Scores, and Grades From Grade 5 (G5) to 8 (G8)

\begin{tabular}{|c|c|c|c|c|c|c|c|c|c|c|c|c|}
\hline \multirow[b]{2}{*}{ Variable } & \multicolumn{12}{|c|}{ Measurement Occasion Grade 5 - Grade 8} \\
\hline & Test $_{\mathrm{G} 5}$ & Test $_{\mathrm{G} 6}$ & Test $_{\mathrm{G} 7}$ & Test $_{\mathrm{G} 8}$ & $\mathrm{ASC}_{\mathrm{G} 5}$ & $\mathrm{ASC}_{\mathrm{G} 6}$ & $\mathrm{ASC}_{\mathrm{G} 7}$ & $\mathrm{ASC}_{\mathrm{G} 8}$ & Grade $_{\mathrm{G} 5}$ & Grade $_{\mathrm{G} 6}$ & Grade $_{\mathrm{G} 7}$ & Grade $_{\mathrm{G} 8}$ \\
\hline Test $_{\mathrm{G} 5}$ & 1 & & & & & & & & & & & \\
\hline Test $_{\mathrm{G} 6}$ & .83 & 1 & & & & & & & & & & \\
\hline Test $_{\mathrm{G} 7}$ & .79 & .81 & 1 & & & & & & & & & \\
\hline Test $_{\mathrm{G} 8}$ & .73 & .77 & .80 & 1 & & & & & & & & \\
\hline $\mathrm{ASC}_{\mathrm{G} 5}$ & .28 & .28 & .26 & .23 & 1 & & & & & & & \\
\hline $\mathrm{ASC}_{\mathrm{G} 6}$ & .27 & .28 & .27 & .25 & .49 & 1 & & & & & & \\
\hline $\mathrm{ASC}_{\mathrm{G} 7}$ & .28 & .29 & .31 & .28 & .45 & .60 & 1 & & & & & \\
\hline $\mathrm{ASC}_{\mathrm{G} 8}$ & .26 & .28 & .30 & .31 & .37 & .50 & .57 & 1 & & & & \\
\hline Grade $_{\mathrm{G} 5}$ & .48 & .44 & .44 & .41 & .35 & .31 & .26 & .20 & 1 & & & \\
\hline Grade $_{\mathrm{G} 6}$ & .54 & .50 & .49 & .46 & .31 & .39 & .32 & .27 & .59 & 1 & & \\
\hline Grade $_{\mathrm{G} 7}$ & .48 & .48 & .48 & .45 & .24 & .37 & .35 & .31 & .48 & .65 & 1 & \\
\hline Grade $_{\mathrm{G} 8}$ & .46 & .47 & .48 & .47 & .24 & .34 & .36 & .41 & .41 & .56 & .63 & 1 \\
\hline$M$ & 100.00 & 112.74 & 125.76 & 139.26 & 2.98 & 2.91 & 2.83 & 2.71 & 4.20 & 3.01 & 3.83 & 3.82 \\
\hline$S D$ & 30.00 & 31.67 & 31.92 & 35.25 & 0.75 & 0.80 & 0.79 & 0.82 & 1.02 & 0.83 & 0.88 & 0.92 \\
\hline
\end{tabular}

Note . Test $=$ Standardized achievement in mathematics; ASC $=$ Math self-concept; Grade = Math grade; G5-G8 = Grade $5-$ Grade 8 . All correlations between variables were statistically significant at $p<.001$. 


\section{Table 4}

Model Fit Statistics for the Respective Longitudinal Structural Equation Models

\begin{tabular}{|c|c|c|c|c|c|}
\hline Model & $\chi^{2}(d f)$ & RMSEA & CFI & TLI & SRMR \\
\hline & \multicolumn{5}{|c|}{ Grade 5 - Grade 7} \\
\hline CLPM $_{\text {G56/G67 }}$ & $359.27(9)$ & .10 & .97 & .89 & .03 \\
\hline CLPM $_{\text {G567 }}$ & $485.80(18)$ & .08 & .96 & .93 & .05 \\
\hline FF-CLPM $_{\mathrm{G} 56 / \mathrm{G} 67}$ & \multicolumn{5}{|c|}{ Saturated $(d f=0)$} \\
\hline FF-CLPM ${ }_{\mathrm{G} 567}$ & $260.11(9)$ & .09 & .98 & .92 & .05 \\
\hline RI-CLPM $_{\mathrm{G} 56 / \mathrm{G} 67}$ & $11.63(3)$ & .03 & .99 & .99 & .01 \\
\hline RI-CLPM $_{\text {G567 }}$ & $51.46(12)$ & .03 & .99 & .99 & .03 \\
\hline & \multicolumn{5}{|c|}{ Grade 6 - Grade 8} \\
\hline CLPM $_{\text {G67/G78 }}$ & 497.01(9) & .12 & .97 & .88 & .03 \\
\hline CLPM $_{\mathrm{G} 678}$ & $477.98(18)$ & .08 & .97 & .94 & .03 \\
\hline FF-CLPM ${ }_{\text {G67/G78 }}$ & \multicolumn{5}{|c|}{ Saturated $(d f=0)$} \\
\hline FF-CLPM ${ }_{\text {G678 }}$ & $137.16(9)$ & .06 & .99 & .97 & .04 \\
\hline $\mathrm{RI}^{-C L P M} \mathrm{G}_{\mathrm{G} 7 / \mathrm{G} 78}$ & $13.77(3)$ & .03 & .99 & .99 & .01 \\
\hline RI-CLPM $_{\mathrm{G} 678}$ & $66.96(12)$ & .03 & .99 & .99 & .03 \\
\hline
\end{tabular}

Note. RMSEA = Root mean square error of approximation; CFI = Comparative fit index; TLI = Tucker-Lewis index; SRMR = Standardized root mean squared residual; CLPM= Cross-lagged panel model; FF-CLPM = Full-forward (Lag-2) cross-lagged panel model; RI-CLPM = Random intercept cross-lagged panel model; G56/G67 =

Models based on data from Grade 5-7 with no equality constraints on lag-1 coefficients over time; G567 = Models based on data from Grade 5-7 with equality constraints on lag-1 coefficients over time; G67/G78 = Data from Grade 6-9 with no equality constraints on lag-1 coefficients over time; G678 = Data from Grade 6-9 with equality constraints on lag-1 coefficients over time. 


\section{Table 5}

Autoregressive and Cross-Lagged Coefficients (Grade 6-Grade 7) for the Different Models

\begin{tabular}{|c|c|c|c|c|c|c|c|c|c|c|c|c|c|c|c|c|c|c|}
\hline \multirow{3}{*}{$\begin{array}{l}\text { Dependent Variable } \\
\text { Model }\end{array}$} & \multicolumn{6}{|c|}{ Test } & \multicolumn{6}{|c|}{ ASC } & \multicolumn{6}{|c|}{ Grade } \\
\hline & \multicolumn{2}{|c|}{ Test } & \multicolumn{2}{|c|}{ ASC } & \multicolumn{2}{|c|}{ Grade } & \multicolumn{2}{|c|}{ ASC } & \multicolumn{2}{|c|}{ Test } & \multicolumn{2}{|c|}{ Grade } & \multicolumn{2}{|c|}{ Grade } & \multicolumn{2}{|c|}{ Test } & \multicolumn{2}{|c|}{ ASC } \\
\hline & $\beta$ & $S E$ & $\beta$ & $S E$ & $\beta$ & $S E$ & $\beta$ & $S E$ & $\beta$ & $S E$ & $\beta$ & $S E$ & $\beta$ & $S E$ & $\beta$ & $S E$ & $\beta$ & $S E$ \\
\hline CLPM $_{\text {G56/G67 }}$ & .75 & .03 & .02 & .02 & .10 & .02 & .55 & .02 & .12 & .02 & .05 & .02 & .50 & .02 & .20 & .03 & .12 & .02 \\
\hline CLPM $_{\text {G567 }}$ & .78 & .02 & .04 & .01 & .07 & .02 & .46 & .01 & .10 & .02 & .09 & .02 & .48 & .02 & .25 & .02 & .11 & .01 \\
\hline FF-CLPM $_{\text {G56/G67 }}$ & .48 & .05 & .02 & .02 & .03 & .03 & .47 & .02 & .09 & .04 & $.04^{\dagger}$ & .02 & .45 & .03 & .16 & .04 & .14 & .02 \\
\hline FF-CLPM G567 & .68 & .04 & .04 & .02 & .05 & .01 & .47 & .02 & .10 & .02 & .08 & .01 & .37 & .02 & .24 & .02 & .11 & .02 \\
\hline RI-CLPM $_{\mathrm{G} 56 / \mathrm{G} 67}$ & .27 & .14 & .08 & .06 & -.05 & .09 & .33 & .04 & $.08^{\dagger}$ & .04 & .07 & .04 & .20 & .09 & .06 & .06 & .23 & .04 \\
\hline RI-CLPM $_{\text {G567 }}$ & .22 & .08 & .07 & .04 & .01 & .05 & .26 & .03 & $.06^{\dagger}$ & .03 & .14 & .04 & .17 & .05 & .06 & .05 & .24 & .03 \\
\hline EB & .42 & .07 & .06 & .02 & .03 & .04 & .40 & .03 & .10 & .07 & .11 & .03 & .38 & .04 & .18 & .07 & .22 & .03 \\
\hline $\mathrm{EB}+$ trimmed & .41 & .06 & .07 & .02 & .03 & .04 & .41 & .02 & .10 & .07 & .11 & .03 & .39 & .04 & .17 & .06 & .23 & .02 \\
\hline CBGPS & .43 & .08 & .06 & .02 & .02 & .02 & .40 & .03 & .12 & .08 & $.10^{\dagger}$ & .05 & .35 & .04 & .20 & .08 & .21 & .03 \\
\hline CBGPS + trimmed & .43 & .06 & .07 & .02 & .03 & .02 & .40 & .02 & $.12^{\dagger}$ & .07 & .12 & .04 & .37 & .03 & .18 & .06 & .22 & .02 \\
\hline
\end{tabular}

Note. All variables were $z$ standardized. ASC = Academic self-concept; CLPM = Cross-lagged panel model; FF-CLPM = Full-forward (Lag-2) cross-lagged panel model; RICLPM = Random intercept cross-lagged panel model; EB = Entropy balancing; CBGPS = Covariate balanced generalized propensity score weighting; G567 = Models based on data from Grade 5-7 with equality constraints on lag-1 coefficients over time; G56/G67 = Models based on data from Grade 5-7 with no equality constraints on lag-1 coefficients over time. Trimmed $=$ Trimmed at $1 \%$. Statistically significant values at $p<.05$ are printed bold.

$\dagger$ one-sided statistically significant. 


\section{Table 6}

Autoregressive and Cross-Lagged Coefficients (Grade 7 - Grade 8) for the Different Models

\begin{tabular}{|c|c|c|c|c|c|c|c|c|c|c|c|c|c|c|c|c|c|c|}
\hline \multirow{3}{*}{$\begin{array}{l}\text { Dependent Variable } \\
\text { Model }\end{array}$} & \multicolumn{6}{|c|}{ Test on } & \multicolumn{6}{|c|}{$\mathrm{ASC}$ on } & \multicolumn{6}{|c|}{ Grade on } \\
\hline & \multicolumn{2}{|c|}{ Test } & \multicolumn{2}{|c|}{ ASC } & \multicolumn{2}{|c|}{ Grade } & \multicolumn{2}{|c|}{ ASC } & \multicolumn{2}{|c|}{ Test } & \multicolumn{2}{|c|}{ Grade } & \multicolumn{2}{|c|}{ Grade } & \multicolumn{2}{|c|}{ Test } & \multicolumn{2}{|c|}{ ASC } \\
\hline & $\beta$ & $S E$ & $\beta$ & $S E$ & $\beta$ & $S E$ & $\beta$ & $S E$ & $\beta$ & $S E$ & $\beta$ & $S E$ & $\beta$ & $S E$ & $\beta$ & $S E$ & $\beta$ & $S E$ \\
\hline CLPM $_{\text {G67/78 }}$ & .75 & .03 & .02 & .02 & .09 & .02 & .51 & .02 & .10 & .02 & .08 & .02 & .49 & .02 & .21 & .02 & .13 & .02 \\
\hline CLPM $_{\text {G678 }}$ & .77 & .02 & $.02^{\dagger}$ & .01 & .09 & .02 & .54 & .01 & .11 & .02 & .07 & .02 & .50 & .02 & .20 & .02 & .13 & .01 \\
\hline FF-CLPM G67/78 & .50 & .04 & .01 & .02 & .03 & .02 & .40 & .02 & $.09^{\dagger}$ & .04 & .06 & .02 & .38 & .02 & .12 & .03 & .11 & .03 \\
\hline FF-CLPM $_{\text {G678 }}$ & .61 & .03 & .02 & .01 & .08 & .01 & .46 & .01 & .11 & .02 & .06 & .02 & .44 & .02 & .17 & .02 & .12 & .02 \\
\hline RI-CLPM $_{\text {G67/78 }}$ & .13 & .09 & .05 & .05 & .02 & .06 & .18 & .04 & .06 & .05 & .05 & .03 & .24 & .04 & .02 & .04 & .12 & .03 \\
\hline RI-CLPM G678 & -.08 & .36 & .04 & .07 & -.07 & .14 & .21 & .04 & .04 & .07 & .03 & .03 & .22 & .04 & -.01 & .09 & .13 & .03 \\
\hline EB & .43 & .07 & .04 & .02 & .04 & .02 & .34 & .03 & .17 & .07 & .17 & .04 & .36 & .04 & $.12^{\dagger}$ & .06 & .16 & .03 \\
\hline $\mathrm{EB}+$ trimmed & .43 & .07 & .04 & .02 & $.03^{\dagger}$ & .02 & .35 & .03 & .17 & .07 & .16 & .03 & .36 & .04 & $.12^{\dagger}$ & .06 & .17 & .03 \\
\hline CBGPS & .43 & .07 & .04 & .02 & .05 & .03 & .31 & .03 & .17 & .07 & .16 & .03 & .36 & .05 & .10 & .06 & .14 & .03 \\
\hline CBGPS + trimmed & .43 & .06 & .04 & .02 & .05 & .03 & .33 & .03 & .17 & .07 & .15 & .03 & .36 & .04 & .12 & .05 & .15 & .03 \\
\hline
\end{tabular}

Note. All variables were $z$ standardized. ASC = Academic self-concept; CLPM = Cross-lagged panel model; FF-CLPM = Full-forward (Lag-2) cross-lagged panel model; RI-

CLPM = Random intercept cross-lagged panel model; EB = Entropy balancing; CBGPS = Covariate balanced generalized propensity score weighting; G678 = Models based on data from Grade 6-8 with equality constraints on lag-1 coefficients over time; G67/G78 = Models based on data from Grade 6-8 with no equality constraints on lag-1 coefficients over time. Trimmed $=$ Trimmed at $1 \%$. Statistically significant values at $p<.05$ are printed bold

${ }^{\dagger} p<.1$. 


\section{Figure 1}

Potential Structural Causal Models for the Reciprocal Relationship Between Self-Concept, Grades, and Test Achievement

(a)

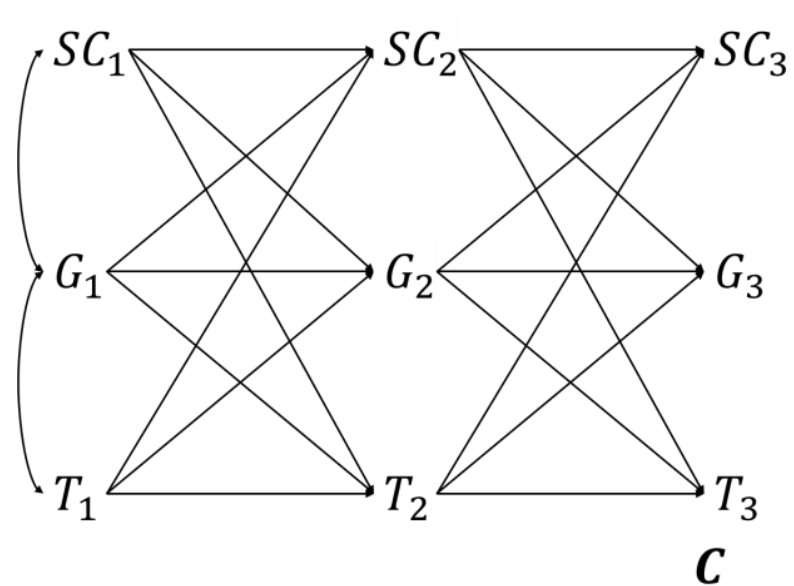

(b)

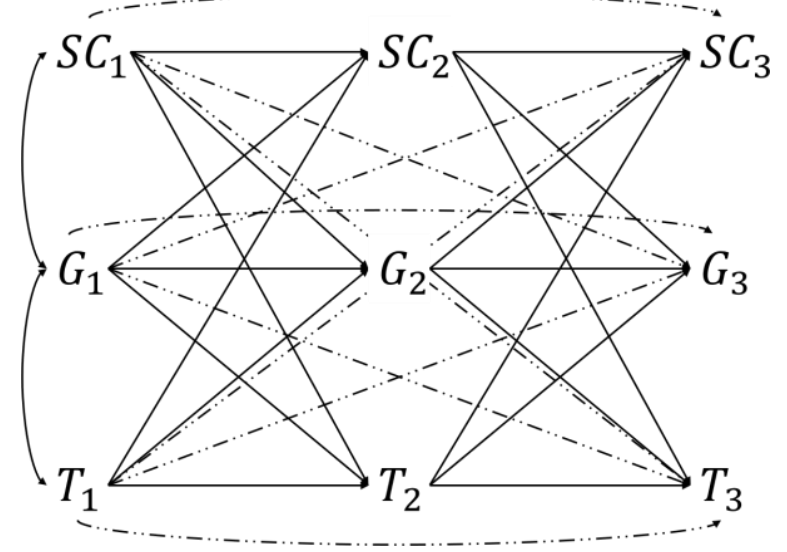

(c)

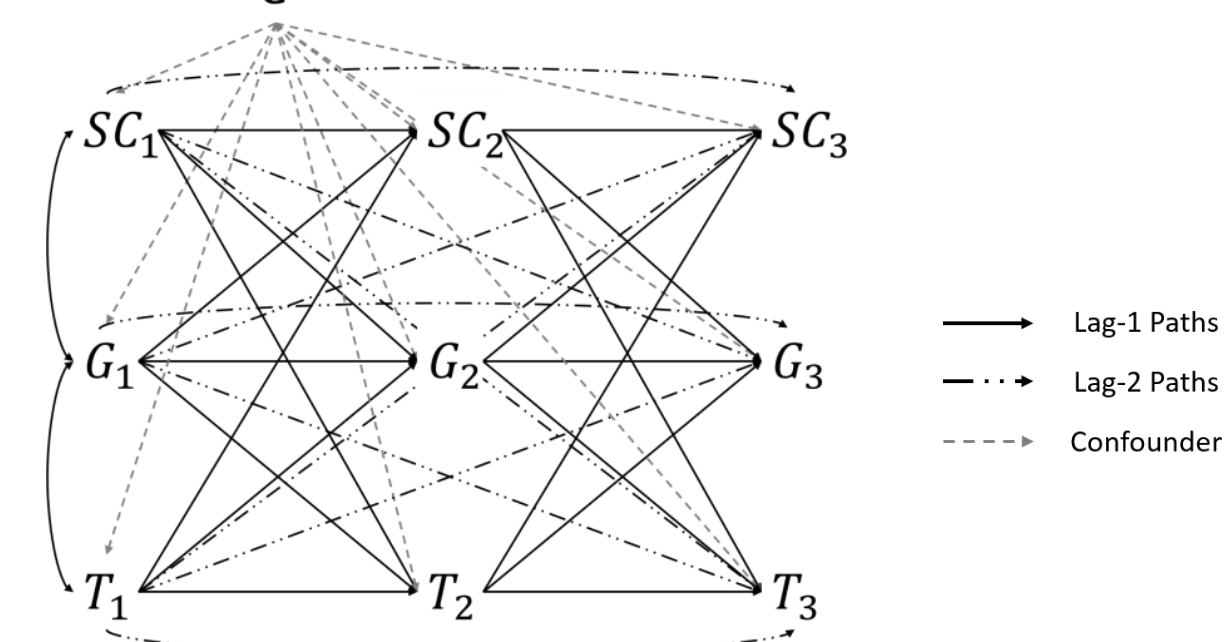

Note. $\mathrm{SC}=$ Self-concept $\mathrm{G}=$ Grades $; \mathrm{T}=$ Test achievement. $\mathrm{C}$ denotes a vector of potential confounders. Indices indicate measurement occasions. 


\section{Figure 2}

Example of the Different Steps When Applying CBGPS for Estimating the Effect of Self-Concept (T2) on Grades (T3)

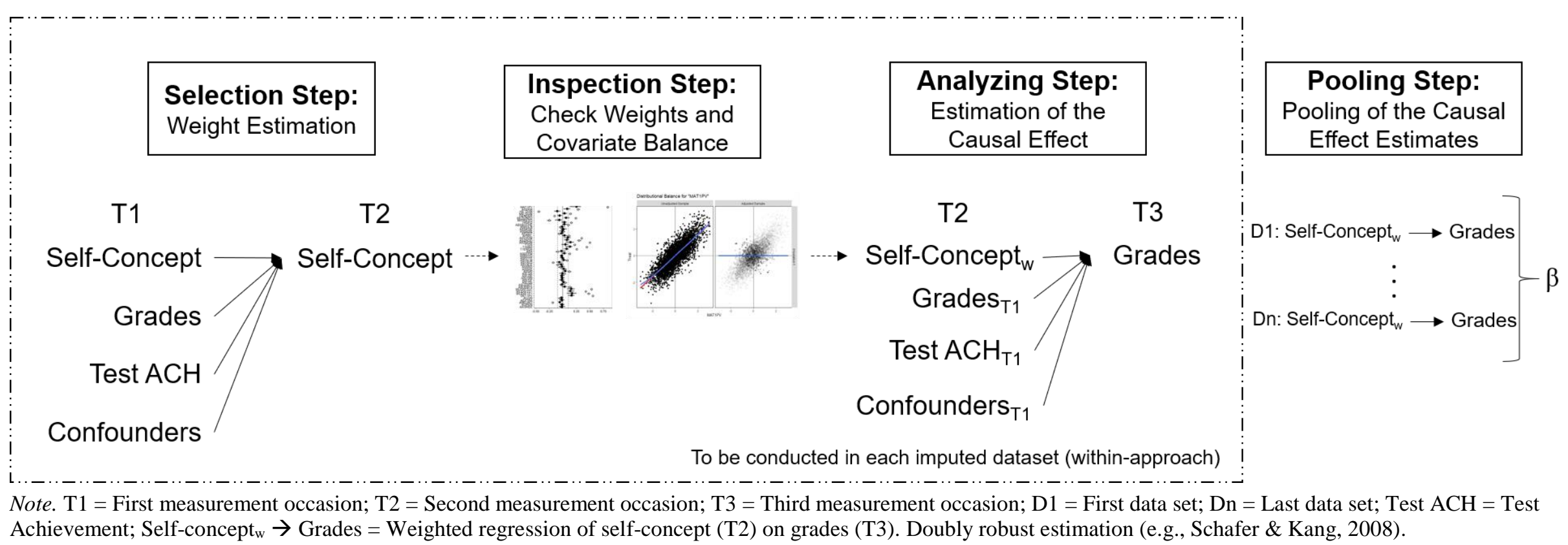




\section{Figure 3}

Covariate Balance Before and After Weighting at T2 Using EB and CBGPS-weighting Summarized Across Imputations

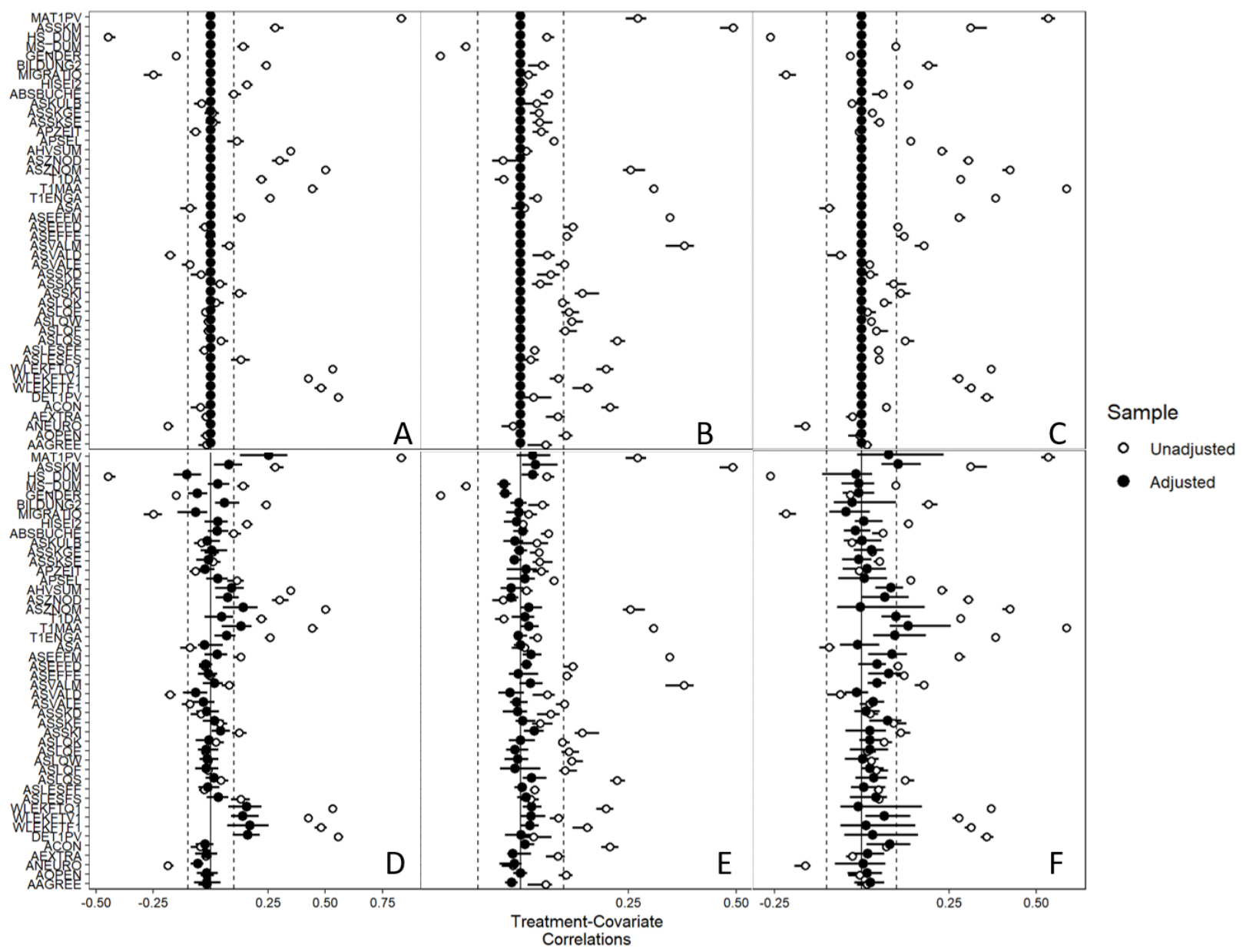

Note. $\mathrm{A}=$ Standardized test achievement $+\mathrm{EB} ; \mathrm{B}=$ Self-concept $+\mathrm{EB} ; \mathrm{C}=$ Grades $+\mathrm{EB} ; \mathrm{D}=$ Standardized test achievement + CBGPS; E = Self-concept + CBGPS; F = Grades + CBGPS. Dashed lines were plotted at $r=.1$. Lines display variation in estimates across imputations. 


\section{Figure 4}

\section{Cross-Lagged Coefficients From Different Modelling Strategies}

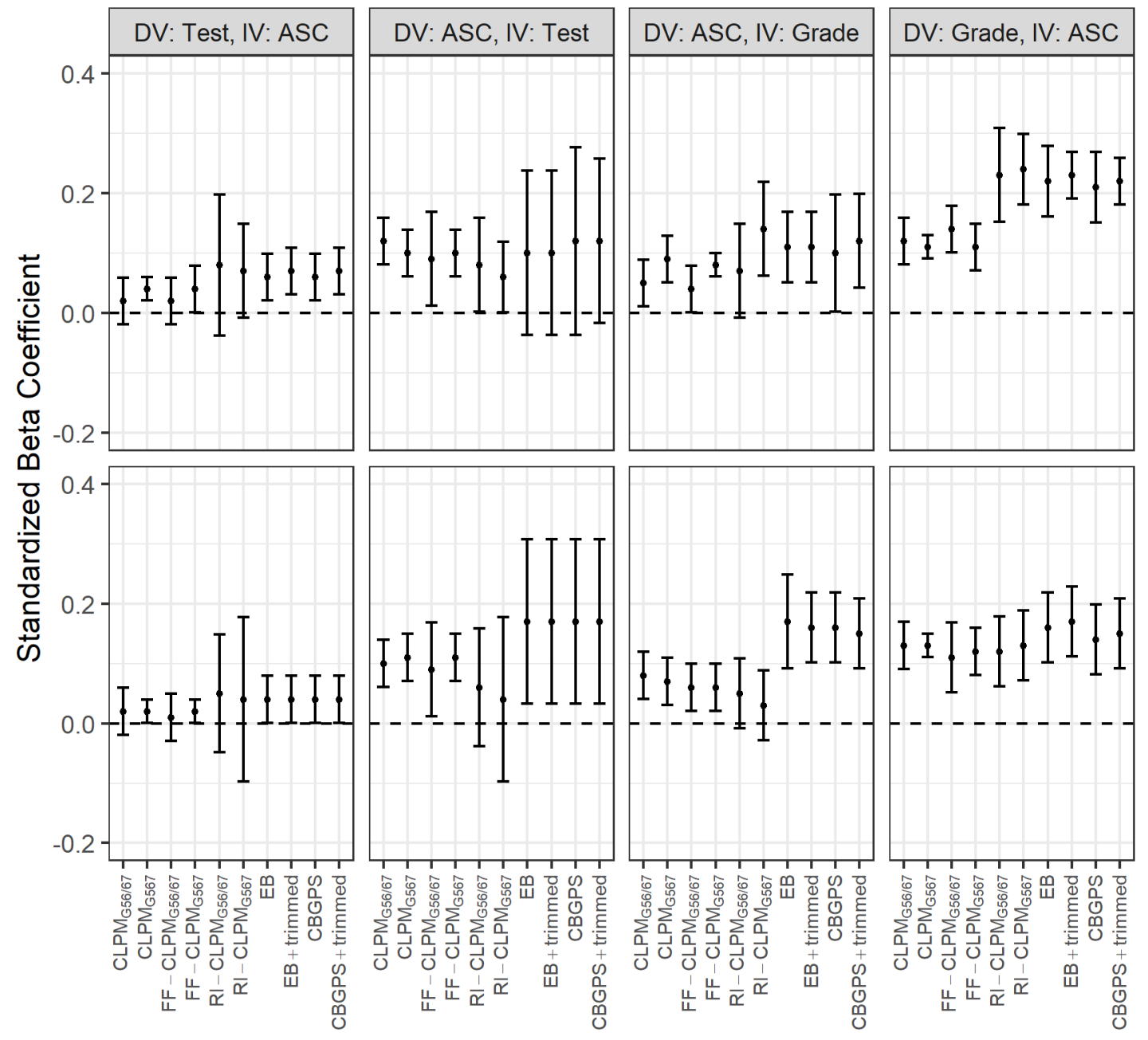

Note. The upper panel displays results considering Grade 5 - Grade 7 data, whereas the lower panel displays results from the Grade 6 - Grade 8 data. In the lower panel, indices 56/67 and 567 represent models 67/78 and 678 from Table 6 . The figure shows cross-lagged coefficients from Table 5 and Table 6 and $95 \%$ confidence intervals. DV = Dependent variable; IV = Independent variable; ASC = Academic self-concept CLPM = Crosslagged panel model; FF-CLPM = Full-forward (Lag-2) cross-lagged panel model; RI-CLPM = Random intercept cross-lagged panel model; EB = Entropy balancing; CBGPS = Covariate balanced generalized propensity score weighting; G567 = Models based on data from Grade 5-7 with equality constraints on lag-1 coefficients over time; G56/G67 = Models based on data from Grade 5-7 with no equality constraints on lag-1 coefficients over time. Trimmed $=$ Trimmed at $1 \%$. 
How causal is a reciprocal effect?

Appendix 


\section{Appendix A1}

\section{A Comprehensive List of All Covariates Considered for EB and CBGPS-Weighting}

\begin{tabular}{|c|c|c|c|c|}
\hline Variable & Statement & Example & Scale & Number of items \\
\hline \multicolumn{5}{|l|}{ Subject-specific self-concept } \\
\hline Mathematics & What applies to you? & $\begin{array}{l}\text { I am good in } \\
\text { mathematics. } \\
\text { I just have no talent for } \\
\text { mathematics. }\end{array}$ & $\begin{array}{l}1 \text { (does not apply at all) } \\
-4 \text { (completely } \\
\text { applies) }\end{array}$ & 4 \\
\hline German & What applies to you? & $\begin{array}{l}\text { I am good inGerman. } \\
\text { I am simply not gifted } \\
\text { for the subject German. }\end{array}$ & $\begin{array}{l}1 \text { (totally disagree) }-4 \\
\text { (agree exactly) }\end{array}$ & 4 \\
\hline English & What applies to you? & $\begin{array}{l}\text { I am good in English. } \\
\text { I am simply not gifted } \\
\text { for English. }\end{array}$ & $\begin{array}{l}1 \text { (totally disagree) }-4 \\
\text { (agree exactly) }\end{array}$ & 4 \\
\hline Intelligence & What applies to you? & $\begin{array}{l}\text { For many tasks, I am } \\
\text { sure in advance that I } \\
\text { will not be able to solve } \\
\text { them because I am not } \\
\text { gifted for it. } \\
\text { I often think I'm not as } \\
\text { smart as others. }\end{array}$ & $\begin{array}{l}1 \text { (totally disagree) }-4 \\
\text { (agree exactly) }\end{array}$ & 4 \\
\hline Reading & $\begin{array}{l}\text { How much do you like } \\
\text { to read? }\end{array}$ & $\begin{array}{l}\text { If I had enough time, I } \\
\text { would read more. } \\
\text { I enjoy reading books. } \\
\text { I find reading } \\
\text { interesting. }\end{array}$ & $\begin{array}{l}1 \text { (totally disagree) }-4 \\
\text { (agree exactly) }\end{array}$ & 7 \\
\hline
\end{tabular}




\section{Mathematics \\ achievement test \\ Reading \\ comprehension in \\ German \\ Listening \\ comprehension in \\ English}

items from areas of

number, space/shape,

measure, functions, and

data/chance

A reading text, for

example a newspaper

article, a poem, or a

short story.

The entire school class

listened to a recording

Two native speakers talked about a scene in the outdoor pool. The pupils had a picture of this scene and had to

decide which child we were talking about.

\section{Subject-specific interests}

Value beliefs German

What applies to you?

When I'm working on a
German assignment, it can happen that I don't

even notice how time

flies.

It's important to me to be good at German.

Value beliefs English What applies to you?

When I'm working on an English assignment, it can happen that I

don't even notice how time flies.

It's important to me to be good at English.

Value beliefs

What applies to you?

multiple choice, open answers, and short

answers

multiple choice, open answers, and short answers

Multiple choice, truefalse questions, short content related open questions

depending on the grade level between 74 and 87 items

depending on the grade level between 60 and 87 items

Depending on the grade level between 27 and

47 items (totally disagree) - 4

(agree exactly) 
happen that I don't even

notice how time flies.

It's important to me to

be good at math.

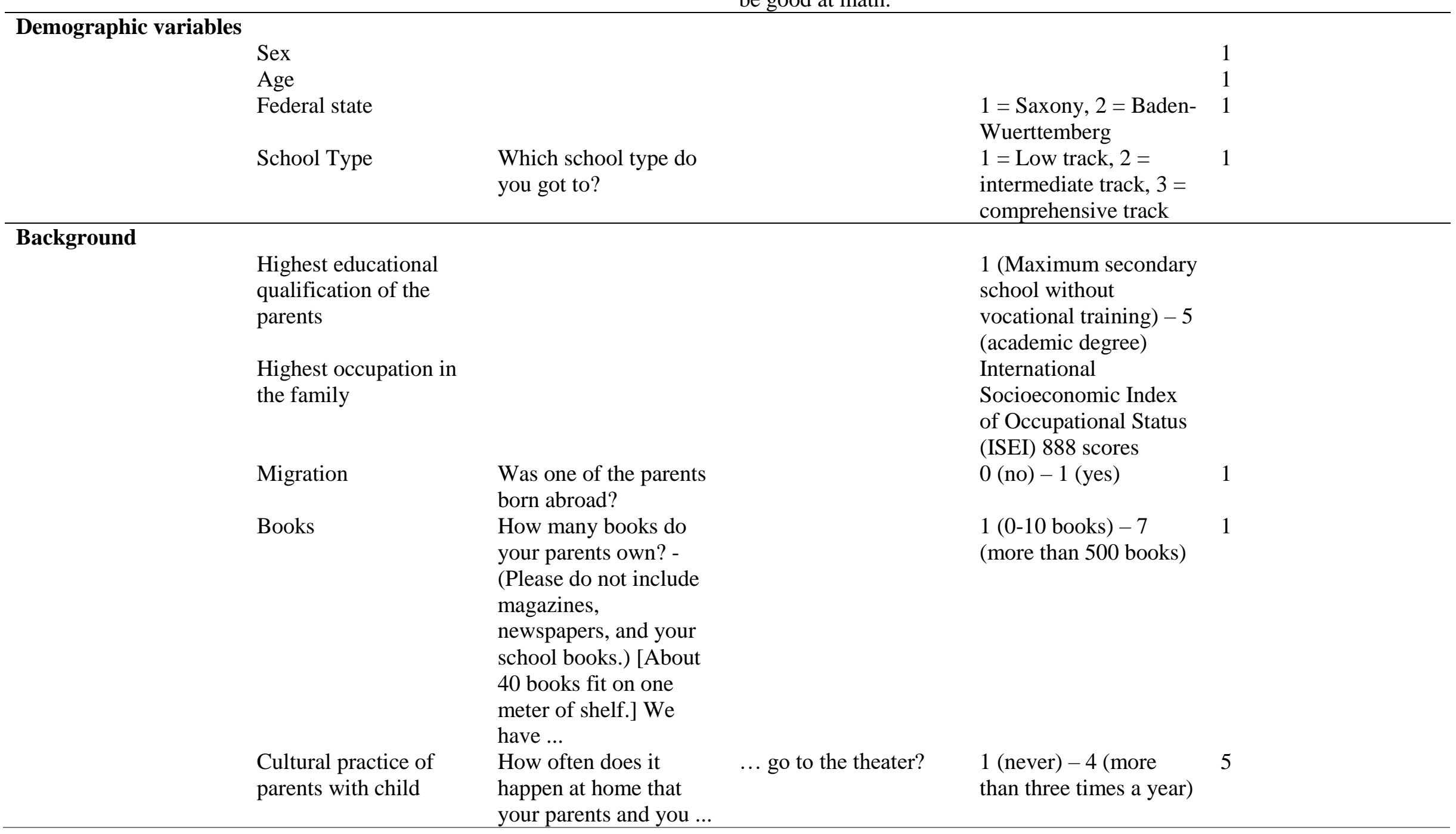




\begin{tabular}{|c|c|c|c|c|c|}
\hline Basic cognitive skills & & $\begin{array}{l}\text { Verbal }(\mathrm{V}) \text {, figural }(\mathrm{F}) \text {, } \\
\text { and quantitative }(\mathrm{Q}) \\
\text { subscale of the KFT4- } \\
12+\mathrm{R}\end{array}$ & & 0 (false) - 1(correct) & $\begin{array}{l}25 \text { items }(\mathrm{F}) \\
20 \text { items }(\mathrm{V}) \\
20 \text { items }(\mathrm{Q})\end{array}$ \\
\hline Structure of everyday & & & & & \\
\hline & $\begin{array}{l}\text { Communication } \\
\text { between parent and } \\
\text { child }\end{array}$ & $\begin{array}{l}\text { How often does it } \\
\text { happen at home that } \\
\text { your parents... }\end{array}$ & $\begin{array}{l}\text {... talk to you about } \\
\text { what you do with your } \\
\text { friends? }\end{array}$ & $\begin{array}{l}1 \text { (never) - } 4 \text { (very } \\
\text { often) }\end{array}$ & 4 \\
\hline & $\begin{array}{l}\text { Structuring of everyday } \\
\text { life by parents }\end{array}$ & $\begin{array}{l}\text { Everyday life at your } \\
\text { home. My parents } \\
\text { make sure that... }\end{array}$ & $\begin{array}{l}\ldots \text { I go to bed at set } \\
\text { times on school days. }\end{array}$ & $\begin{array}{l}1 \text { (totally disagree) }-4 \\
\text { (agree exactly) }\end{array}$ & 7 \\
\hline Parents' support & & & & & \\
\hline & $\begin{array}{l}\text { Parents' time for } \\
\text { school-related purposes }\end{array}$ & $\begin{array}{l}\text { How do you assess the } \\
\text { following statements? } \\
\text { I have enough time and } \\
\text { energy... }\end{array}$ & $\begin{array}{l}\ldots \text { to talk intensively } \\
\text { with my child about } \\
\text { their school day. }\end{array}$ & $\begin{array}{l}1 \text { (totally disagree) }-4 \\
\text { (agree exactly) }\end{array}$ & 6 \\
\hline & $\begin{array}{l}\text { Parents' self- } \\
\text { assessment of their own } \\
\text { abilities }\end{array}$ & $\begin{array}{l}\text { How do you assess the } \\
\text { following statements? }\end{array}$ & I was a good student. & $\begin{array}{l}1 \text { (totally disagree) }-4 \\
\text { (agree exactly) }\end{array}$ & 6 \\
\hline Grades & & & & & \\
\hline & $\begin{array}{l}\text { Certificate grade } \\
\text { German }\end{array}$ & $\begin{array}{l}\text { What grades did you } \\
\text { get on your last } \\
\text { certificate? }\end{array}$ & & $1-6$ & 1 \\
\hline & $\begin{array}{l}\text { Certificate grade } \\
\text { mathematics }\end{array}$ & $\begin{array}{l}\text { What grades did you } \\
\text { get on your last } \\
\text { certificate? }\end{array}$ & & $1-6$ & 1 \\
\hline & $\begin{array}{l}\text { Certificate grade } \\
\text { English }\end{array}$ & $\begin{array}{l}\text { What grades did you } \\
\text { get on your last } \\
\text { certificate? }\end{array}$ & & $1-6$ & 1 \\
\hline Well-being, joy of rea & $\begin{array}{l}\text { ng, etc. } \\
\text { Physical well-being }\end{array}$ & $\begin{array}{l}\text { First, we would like to } \\
\text { know something about } \\
\text { your well-being ... } \\
\text { In the last week... }\end{array}$ & ... I felt sick. & 1 (never) - 5 (always) & 4 \\
\hline
\end{tabular}




\begin{tabular}{|c|c|c|c|c|c|}
\hline & Emotional well-being & $\begin{array}{l}\text {... then something about } \\
\text { how you feel- In the }\end{array}$ & $\begin{array}{l}\text {... I laughed a lot and } \\
\text { had fun. }\end{array}$ & 1 (never) - 5 (always) & 4 \\
\hline & Self-worth & $\begin{array}{l}\text { last week ... } \\
\text {... and what you think } \\
\text { of yourself- In the last } \\
\text { week ... }\end{array}$ & $\begin{array}{l}\ldots \text { I was proud of } \\
\text { myself. }\end{array}$ & 1 (never) - 5 (always) & 4 \\
\hline & Family & $\begin{array}{l}\text { The next questions are } \\
\text { about your family- In } \\
\text { the last week ... }\end{array}$ & $\begin{array}{l}\text {... I got on well with } \\
\text { my parents. }\end{array}$ & 1 (never) - 5 (always) & 4 \\
\hline & Joy of reading & $\begin{array}{l}\text { How much do you like } \\
\text { to read? }\end{array}$ & $\begin{array}{l}\text { If I had enough time, I } \\
\text { would read more. }\end{array}$ & $\begin{array}{l}1 \text { (totally disagree) }-4 \\
\text { (agree exactly) }\end{array}$ & 4 \\
\hline Effort & & & & & \\
\hline & Absenteeism & $\begin{array}{l}\text { How often this school } \\
\text { year have you... }\end{array}$ & $\begin{array}{l}\text {... played truant in } \\
\text { certain subjects }\end{array}$ & $\begin{array}{l}1(\text { not at all })-4(5 \\
\text { times or more })\end{array}$ & 6 \\
\hline Personality & & & & & \\
\hline & Extraversion & $\begin{array}{l}\text { How much do the } \\
\text { following statements } \\
\text { apply to you? I am } \\
\text { someone who ... }\end{array}$ & $\begin{array}{l}\text {...is talkative, likes to } \\
\text { chat. }\end{array}$ & $\begin{array}{l}1 \text { (totally disagree) }-4 \\
\text { (agree exactly) }\end{array}$ & 8 \\
\hline & Agreeableness & $\begin{array}{l}\text { How much do the } \\
\text { following statements } \\
\text { apply to you? I am } \\
\text { someone who ... }\end{array}$ & $\begin{array}{l}\ldots \text { is helpful and } \\
\text { selfless to others. }\end{array}$ & $\begin{array}{l}1 \text { (totally disagree) }-4 \\
\text { (agree exactly) }\end{array}$ & 8 \\
\hline & Conscientiousness & $\begin{array}{l}\text { How much do the } \\
\text { following statements }\end{array}$ & $\begin{array}{l}\text {...gets things done } \\
\text { thoroughly. }\end{array}$ & $\begin{array}{l}1 \text { (totally disagree) }-4 \\
\text { (agree exactly) }\end{array}$ & 9 \\
\hline
\end{tabular}


apply to you? I am

someone who ...

Neuroticism

Openness

How much do the

following statements

apply to you? I am

someone who ...

How much do the

following statements

...worries a lot.

1 (totally disagree) -4

(agree exactly)

apply to you? I am

someone who $\begin{array}{ll}\text {...is interested in many } & 1 \text { (totally disagree) }-4 \\ \text { things. } & \text { (agree exactly) }\end{array}$

$\begin{array}{ll}\text {...is interested in many } & 1 \text { (totally disagree) } \\ \text { things. } & \text { (agree exactly) }\end{array}$

...is in

Note. Constructs with multiple items were considered as a scale. Negatively formulated items were reverse-coded. 


\section{Appendix A2}

\section{Exemplary Mplus Code}

TITLE: Your title goes here

DATA:

FILE = "Path/data.dat";

TYPE= imputation;

VARIABLE:

NAMES $=\ldots$;

USEVAR = MAT1 MAT2 MAT3 ASC BSC CSC G1 G2 G3;

cluster $=$ IDschule;

MISSING=.;

ANALYSIS:

MODEL = NOCOV;

ESTIMATOR=MLR;

TYPE $=$ COMPLEX;

\section{MODEL:}

!Create two individual factors (random intercepts)

R_ACH by MAT1@1MAT2@1MAT3@1;

R_ASC by ASC@1BSC@1CSC@1;

R_GbyG1@1G2@1G3@1;

!Create within-person centered variables

c_m1 by MAT1@1; c_m2 by MAT2@1; c_m3 by MAT3@1;

c_s1 by ASC@1; c_s2 by BSC@1; c_s3 by CSC@1;

c_n1 by G1 @1; c_n2 by G2@1; c_n3 by G3@1;

!Constrain the measurement error variances to 0

MAT1-G3@0;

!Estimate the lagged effects between within centered vars

c_m2-c_m3 pon c_m1-c_m2;

c_s2-c_s3 pon c_s1-c_s2;

c_n2-c_n3 pon c_n1-c_n2;

c_m2-c_m3 pon c_s1-c_s2;

c_s2-c_s3 pon c_m1-c_m2;

c_n2-c_n3 pon c_m1-c_m2;

c_m2-c_m3 pon c_n1-c_n2;

c_n2-c_n3 pon c_s1-c_s2;

c_s2-c_s3 pon c_n1-c_n2;

! Estimate covariance between random intercepts (In CLPM: Not estimated) R_ACH R_ASC R_G WITH R_ACH R_ASC R_G;

! Estimate covariance at $\mathrm{T} 1$

c_m1 c_s1 c_n1 WITH c_m1 c_s1 c_n1 ; 
!Estimate residual covariances

c_m2 c_s2 c_n2 WITH c_m2 c_s2 c_n2;

c_m3 c_s3 c_n3 WITH c_m3 c_s3 c_n3;

! in CLPM: Fix VAR of RIs to zero (this is automatically freely estimated in RI-CLPM)

! R_ACH@0;

! R_ASC@0;

! R_N@0;

OUTPUT:

stdyx stdy; 


\section{Appendix A3}

\section{Exemplary R Code}

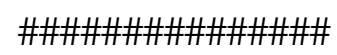

\#\# Weight data \#\#

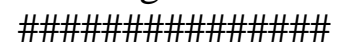

\#\# Exemplary code for estimating the causal effect of self-concept (SC; T2) and a vector of \#\# covariates (COV, T1) on grades (G; T3) using CBGPS weighting

library(MatchThem)

weighted.datasets $<-$ weightthem $\left(S_{-} C_{-} T 2 \sim\right.$ SC_T1 + G_T1 + ACH_T1 + COV_T1, datasets $=$ dat.mids, approach ='within', method ='cbps', estimand = "ATE")

\#\# Check Balance \#\#

library(cobalt)

bal.tab(weighted.datasets)

love.plot(weighted.datasets,stats="correlations", shapes = c("circle filled", "circle"), labels = TRUE, wrap $=20$, stars="raw")

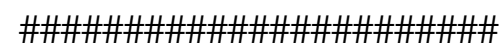

\#\# Estimate causal effect \#\#

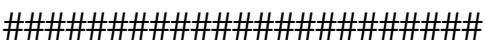

library(survey)

desate<- survey::svydesign(id= IDSCHULE, weights= weights, data=wd) \# no trim desatet<- survey::svydesign(id= IDSCHULE, weights= $\sim$ weights_trim, data=wd) \# trim

ate_cbgps <- with(desate, $\left.\operatorname{svyglm}\left(\mathrm{GT} 3 \sim \mathrm{SCT} 2+\mathrm{COV} \_\mathrm{T} 1\right)\right)$

ate_cbgps_trim <- with(desatet, svyglm $($ GT3 SCT2 + COV_T1)) 